\title{
Use of a choice-based survey approach to characterise fishing behaviour
} in a scallop fishery

Shepperson, Jennifer; Lambert, Gwladys; Murray, Lee; Mackinson, Steve; Bell, Ewen; Kaiser, Michel

\section{Environmental Modelling and Software}

DOI:

10.1016/j.envsoft.2016.09.013

Published: 01/12/2016

Peer reviewed version

Cyswllt i'r cyhoeddiad / Link to publication

Dyfyniad o'r fersiwn a gyhoeddwyd / Citation for published version (APA):

Shepperson, J., Lambert, G., Murray, L., Mackinson, S., Bell, E., \& Kaiser, M. (2016). Use of a choice-based survey approach to characterise fishing behaviour in a scallop fishery.

Environmental Modelling and Software, 86, 116-130.

https://doi.org/10.1016/j.envsoft.2016.09.013

\footnotetext{
Hawliau Cyffredinol / General rights

Copyright and moral rights for the publications made accessible in the public portal are retained by the authors and/or other copyright owners and it is a condition of accessing publications that users recognise and abide by the legal requirements associated with these rights.

- Users may download and print one copy of any publication from the public portal for the purpose of private study or research.

- You may not further distribute the material or use it for any profit-making activity or commercial gain

- You may freely distribute the URL identifying the publication in the public portal ?
}

Take down policy

If you believe that this document breaches copyright please contact us providing details, and we will remove access to the work immediately and investigate your claim. 


\section{Use of a choice-based survey approach to characterise fishing behaviour in a scallop fishery}

Jennifer Shepperson ${ }^{1,2}$, Lee G. Murray ${ }^{1}$, Steven Mackinson², Ewen Bell², Michel J. Kaiser ${ }^{1}$

${ }^{1}$ School of Ocean Sciences, Bangor University, Askew Street, Menai Bridge, Anglesey, LL59 5AB

${ }^{2}$ Centre for Environment, Fisheries, and Aquaculture Science, Lowestoft Laboratory, Pakefield Road, Lowestoft, NR33 OHT

Corresponding author:

Jennifer Shepperson

School of Ocean Sciences, Bangor University, Askew Street, Menai Bridge, Anglesey, LL59 5AB

Phone: +44 1248388501

Email: j.shepperson@bangor.ac.uk

\section{Highlights}

Data was collected directly from fishers to better understanding fishing behaviour. Face to face interviews and a conjoint analysis were completed with scallop fishers. Foraging and environmental parameters central to patch choice were identified.

Different strategies of patch choice were identified, and verified against vessel data. These relevant and reliable data could lead to a more realistic behavioural model.

\section{Abstract}

The predictability of fisher behaviour is an area of considerable uncertainty in fisheries management models. Fisher-derived data could underpin a better understanding, and more realistic predictions, of fishing behaviour. Face to face interviews and a choice-based survey were conducted with scallop fishers to collect foraging parameters that could inform a model of fishing behaviour, and to better understand patch choice behaviour. Importantly, we validated survey data against vessel monitoring system and logbook data where possible, demonstrating a good level of accuracy. Environmental parameters central to patch choice were determined (e.g. wave height, distance to port), and three strategies of patch choice behaviour were identified, termed quantity maximiser, quality maximiser, and efficient fisher. Individuals' VMS and logbook data further confirmed and explained these behavioural patterns. This approach provided reliable, highly relevant data for the parameterisation of a fisheries behavioural model, which could lead to more robust and realistic predictive fisheries models. 


\section{Keywords}

Individual based model, participatory modelling, fisher knowledge, fisher behaviour, conjoint analysis, fisheries

1. Introduction

1.1. We need trusted predictive models for effective fisheries management

Hunter-gatherers, such as fishers, typically lack trust in the scientific evidence that underpins management controls and policy. This phenomenon is termed the 'credibility crisis' (Röckmann et al., 2012). Fishers often express the opinion that data collected by scientists do not sufficiently reflect the status of their fishery, leading to inappropriate management conclusions (Bergmann et al., 2004). The integration of public participation in science has been demonstrated to address some of the concerns surrounding credibility and uncertainty in fisheries (Voinov and Bousquet, 2010; Yates, 2014). In particular, participatory modelling can alleviate some of the tensions between scientists and fishers, through addressing questions surrounding the credibility and legitimacy of scientific advice based on 'black box' models (Röckmann et al., 2012; Thébaud et al., 2014). Quantitative and qualitative scientific models are the primary tool for generating advice for the purpose of natural resource management (Röckmann et al., 2012). Accordingly, there is a need to adopt approaches that assist in the development of more realistic, credible and trusted predictive management models, capable of predicting both ecological and economic impacts of novel future scenarios (Fulton et al., 2011; Reeves et al., 2009; Wilen et al., 2002).

1.2. Predictive models require a better understanding of fishing behaviour.

Whilst the long term sustainability objectives of fishers and scientists are aligned (Kraak et al., 2010), in the short term fishers may be working to different priorities that operate under different spatial and time scales (Röckmann et al., 2012). Management measures that lead to short term reductions in fishing effort typically result in short term economic losses for some fishers. It is necessary to understand fishers' tolerance and capacity to cope with change to be able to understand which measures would engender support compared to those that are unacceptable. We need to understand how fishers will respond to management in terms of the spatial and temporal displacement of effort. If we can understand and predict the scope for fishers' compensatory activity following management 
restrictions, we can calculate realistic economic impacts of management, and reach more agreeable management solutions.

Nevertheless, the predictability of fishing behaviour is an area of considerable uncertainty in fisheries management (Fulton et al., 2011). Human decision-making drives spatial patterns of fishing effort (Hilborn, 2007; Plagányi et al., 2014). We must understand what underlies these fishing decisions, regarding where and when to fish, if we are to understand how fishing behaviour underpins the spatial and temporal patterns in fishing activity that arise from external factors. Hilborn (2007) stated that "managing fisheries is managing people" and so effective management requires an "understanding of the motivation of fishermen and designing a management regime that aligns societal objectives with the incentives provided to fishermen". This notion has been expressed and reiterated by many fishery scientists over the decades (Bucaram et al., 2013; Hallwass et al., 2013; Wilen, 2006, 1979), yet a generation of 'command and control' fishing policies, where top down legislative measures prescribe where and when fishermen can fish, has somewhat failed to take account of the societal and economic dimensions of fisheries (Bucaram and Hearn, 2014; Bucaram et al., 2013; Wilen, 2006). Environmental policies are generally developed centrally, based on the assumption that resource users will respond homogenously to management actions (Gelcich et al., 2005). Whilst fishers' responses to management options may be deterministic, responses are likely to vary between groups and among individuals which necessitates a thorough understanding of the system to make realistic predictions about the effectiveness of management (Gelcich et al., 2005).

1.3. Individual based models could work from a behavioural perspective, but are data intensive.

Individual based models (IBMs) are considered better for predicting individual responses to novel conditions compared to numerical modelling, as individuals can respond to experienced conditions to maximise an objective function (such as fitness) (Grimm and Railsback, 2005; Railsback, 2001). In a fishery, the objective function could be to maximise the economic return (equivalent to fitness), but it could also be influenced by a range of social and environmental factors (Abernethy et al., 2007). Despite the demonstrated utility of theoretical individual based models (Cabral et al., 2010; Ruiz-Pérez et al., 2011; Soulié and Thébaud, 2006), there are relatively few applications of IBMs to real life fisheries (see Bastardie et al., 2014, 2010; Dowling et al., 2012), perhaps due to the limited understanding of fisher behaviour. Vessel monitoring system (VMS) and logbook data (which when linked provide spatially resolved catch records) are increasingly used to investigate fishing 
behaviour (Lee et al., 2010; Murray et al., 2011). While VMS data can offer valuable insights into where and when fishing occurs, it does not impart much insight into the decision making process that resulted in the observed patterns of fishing effort. Fishers' data can provide insights into the decision making at a finer scale than can be inferred from VMS data alone. For example, by collecting data directly from fishers through surveys, it could be possible to identify the objective function of fishers, and thereby determine to what extent profit maximisation is actually driving fishing behaviour in relation to other drivers (Abernethy et al., 2007; Christensen and Raakjær, 2006). This information could inform the behavioural parameters used to develop an IBM of fishing behaviour and thereby predict more realistic and adaptive behavioural patterns in the fishery.

1.4. Participatory modelling can make models more transparent and realistic, increasing trust.

It is increasingly acknowledged that better management decisions can be implemented when stakeholders are engaged in the decision making process, e.g. through participatory modelling (Gelcich et al., 2008; Mackinson 2011; Voinov and Bousquet, 2010). Stakeholders can be involved in; 1) framing the problem and purpose of the model, 2) using and evaluating the model (indirect participation), and 3) directly contributing to model construction (direct participation). Direct participation can increase support, interest and legitimacy (Mackinson and Wilson, 2014; Röckmann et al., 2012). The present study used questionnaires and a conjoint analysis technique to collect data directly from fishers to better understand fishing behaviour, in a first step towards a participatory modelling approach.

Conjoint analysis and related choice modelling methods are used in market research, to evaluate respondent preferences for a number of products with varying features (Green and Srinivasan, 1990). Conjoint analysis quantifies how an individual values a given product with a number of specific features or attributes, so determining which of the features of the product are preferred (Alriksson and Öberg, 2008). Rather than directly asking respondents what they prefer in a product or what influences their decision, a conjoint analysis simulates a more realistic choice context; i.e. respondents cannot simply state that all attributes are important, they are forced to rank them through making trade-offs between products (Orme, 2010). For example, a fisher is likely to state that the sea state, distance to port, and expected catch rate are all crucial in deciding where to fish. Nevertheless, this information would not be very meaningful when trying to understand the choices a fisherman makes when deciding where to fish (e.g. what is the trade-off between sea state [risk] and catch rate?). Whilst conjoint analysis has been used widely in marketing, healthcare, quality 
management and transportation studies, it has been used less often in an environmental context, although it is increasing in use (see Alriksson and Öberg, 2008 for review). In fisheries, conjoint analyses have been used to investigate the importance of fisheries management objectives (Wattage et al., 2005), and perceived impacts of regulatory obligations (Hadjimichael et al., 2013). We propose that a conjoint analysis may also be a useful technique to elicit behavioural data from fishers that could be used to determine response thresholds within a model context.

\subsection{Aims}

The present study sought to determine whether it was possible to elicit realistic and reliable behavioural data from scallop fishers, using a questionnaire survey and conjoint analysis. The specific objectives were to i) further our understanding of fishing behaviours, focussing on the limiting factors and relationships between fishing behavioural parameters and fisher/vessel characteristics; ii) demonstrate the value of conjoint analysis for understanding patch choice behaviour; iii) characterise the behavioural characteristics of fishers, highlighting heterogeneity, and iv) provide evidence for the validity of such survey data. 


\section{Methods}

\subsection{Conjoint Analysis Design}

A conjoint analysis was applied by conceptualising a fishing patch as a commercial product for respondents to choose between, with variable attributes (Table 1). Fishers were presented with a choice of fishing patches with different attribute levels and were asked to select the patch in which they would fish preferentially. Different levels of an attribute refer to the actual details of a product, e.g. if one of the patch attributes is sea state, the levels could be calm, moderate, or rough. The survey was designed to elicit a fisher's preferences for particular patch conditions, in terms of where they would rather fish using their current vessel. Understanding fishers' preferences would identify important attributes that influence fishers' decisions on where to fish, and the variation among individual fishers. An adaptive choice based conjoint (ACBC) survey was constructed and fielded in Sawtooth Software SSI Web v.8.2.4. The ACBC survey design was selected as the most appropriate as it is capable of handling small sample sizes, and a larger number of attributes and levels. In addition, the survey is adaptive, in that the software automatically and continually tailors the choices presented to the respondent according to their previous answers, resulting in a shorter interview with a greater level of respondent engagement (Sawtooth Software Inc., 2014).

Attributes and levels were chosen through informal discussion with relevant experts, including a researcher familiar with the conjoint analysis technique, scientists at the Centre for Environment, Fisheries, and Aquaculture Science (Cefas) and Bangor University, and a well-respected fisher within the scallop industry. A total of six attributes were used in this study, with a combined total of 26 levels between them. The levels for each attribute were selected such that they were relevant to inshore scallop fisheries (Table 1). Patches were attributed with an expected tow quality, i.e. how many scallops the fisher could expect to catch. However, it was necessary to standardise this catch rate so that it was relevant to different sized vessels. Vessels fish with different numbers of dredges depending on their size, therefore catch rates can be standardised as scallop weight per dredge, per tow hour. However, providing a catch rate of scallop weight per dredge hour in the conjoint analysis would require a respondent to repeatedly upscale this up to the catch rate relevant to their vessel to evaluate the patch, which would add substantially to the complexity of the survey. It was therefore decided to class expected tow quality as good, average or poor tows in the patch attributes, and to ask fishers to define what they consider as a good, average or poor tow prior to the survey. 
Table 1. Attributes and their levels used to differentiate between fishing patches in the conjoint analysis.

\begin{tabular}{|c|c|c|}
\hline Attribute & Levels & Explanation \\
\hline Sea State & $\begin{array}{l}\text { Calm, slight, moderate, } \\
\text { rough, very rough, high }\end{array}$ & $\begin{array}{l}\text { This refers to the sea conditions of a patch, derived } \\
\text { from a combination of the wave height and wind } \\
\text { speed. }\end{array}$ \\
\hline Distance to Port & $5,10,20,30,50,80$ & $\begin{array}{l}\text { The distance of a fishing patch from a vessel's port } \\
\text { location, in nautical miles. }\end{array}$ \\
\hline Tow Quality & Low, average, high & $\begin{array}{l}\text { The catch per unit effort of a fishing patch, i.e. how } \\
\text { many bags of scallops a fisher would expect to catch } \\
\text { in a one hour tow. }\end{array}$ \\
\hline Meat Quality & $\begin{array}{l}\text { Low }(12 \%) \text {, average } \\
(16 \%) \text {, high }(20 \%)\end{array}$ & The yield of the meat inside of the scallop. \\
\hline Roe Status & Roe empty, roe full & $\begin{array}{l}\text { The reproductive status of the scallop. Roe refers to } \\
\text { the gonads of the scallop; a scallop with a full roe is } \\
\text { more valuable than a scallop with empty roe. }\end{array}$ \\
\hline Cobble & $\begin{array}{l}1 \%, 10 \%, 20 \%, 30 \% \\
50 \%, 80 \%\end{array}$ & $\begin{array}{l}\text { This refers to the ground type, and how much stone } \\
\text { the dredges pick up. A higher proportion of rocks in } \\
\text { the dredges would result in longer sorting times, and } \\
\text { potentially more damage to the gear and the catch. }\end{array}$ \\
\hline
\end{tabular}

Each of the attribute levels has a particular value for the respondent, influencing how much they like the product; termed the utility. In this analysis, instead of products, there were fishing patches that were described by attributes such as sea state or distance to port. Within an attribute (e.g. sea state) there were different levels (e.g. rough, moderate, calm). Following the ACBC survey, the importance of each attribute, and the utility of each level was calculated using Sawtooth Software. The importance of an attribute relates to which attribute had the biggest influence on a respondent's patch choice, and the utility of each level relates to how much positive or negative influence that level has on the respondent's patch choice.

\subsubsection{The Survey}

The conjoint survey consisted of three different sections; demographic data collection, a screening section, and the choice task. Fishers were first presented with possible fishing patches in what is called the screening section; fishers simply indicated if it was possible or not possible that they would fish in each of the fishing patches, based on the varying attribute levels shown. This identified a set of possible fishing patches that fishers were later asked to choose between. During this screening section, the software continually analysed 
respondent answers for non-compensatory screening rules, where a respondent systematically avoided an attribute level (e.g. high sea state). It then automatically asked the respondent if the level was completely unacceptable, and could remove it from subsequent questions. The software also screened for patch conditions that were an absolute requirement. For example, a respondent may only select patches that are less than 30 miles away. When presented with possible unacceptable or must-have options, a 'none of the above' option was included to reduce the chance of marking simply undesirable levels as completely unacceptable. This adaptive nature of the ACBC means that the questions gradually become more relevant to each individual, allowing a broader scope to the survey as a greater range of attributes can be tested initially. This approach is also more engaging for participants, which results in higher quality data (Sawtooth Software Inc., 2014).

In the choice task section patches that were highlighted as possible fishing patches during the previous screening section were then presented in groups of three. Respondents chose the fishing patch that they preferred the most out of the three presented. The preferred patch from each group of three was then presented in the next round, until through an iterative process of elimination, respondents finally eliminated all but their most preferred fishing patch. The aim of the survey was not specifically to reach this preferred patch concept, but to analyse the trade-off decisions made by the respondent (which become increasingly difficult) as the patches become more similar in their attributes.

\subsection{Semi-structured Questionnaire Survey Design}

A semi-structured questionnaire was conducted alongside the conjoint analysis, to elicit further behavioural parameters and vessel characteristics from the fishers. The questionnaire was also used to gain input on the model design in relation to management scenarios. The questionnaire consisted of five sections: (1) vessel characteristics such as ownership, size, catching power, and crew details; (2) limiting factors and extreme restrictions to fishing, such as weather conditions, maximum limiting distances, and limits to the time spent at sea; (3) behavioural parameters related to average fishing conditions, such as the normal time spent at sea; (4) economic requirements of the vessel, such as a minimum viable catch, and the costs of fishing; and (5) the ways in which management actions have affected fishing activity, and opinions in relation to management and the use of an IBM simulation tool.

\subsection{Fielding the Survey}


Individual fishers on the Isle of Man were contacted by email and then followed up with a phone call to explain more about the project and to arrange a time to meet face to face to complete the interview. The majority of interviews took place on fishing vessels or at the office of the producer organisation. The whole survey could be completed in 45 minutes, of which the conjoint analysis took from 7 to 25 minutes. Nevertheless, many fishers digressed additional useful contextual information, resulting in longer survey times. Whilst survey time could have been minimised, the additional discussion was also viewed as important for building relationships of trust. This data collection was subject to Bangor University's ethics approval process.

\subsection{Data Analysis}

A conjoint utility indicates a fisher's preference for each level within each attribute. The conjoint utilities were calculated with a built-in Sawtooth software Hierarchical Bayes (HB) tool, to determine the utility score for each level of each attribute for each individual respondent (Sawtooth Software Inc., 2014). The HB tool is used to overcome the problem of sparse information, as each respondent only provides a small amount of information on a proportion of the hundreds of possible patch combinations within the survey. Instead of estimating each respondent's utilities individually, the HB algorithm estimates the difference between each respondent's individual data and average utilities for the entire sample. It then adjusts each individual's utilities, depending on the variability in the sample average; the more variance in the sample averages, the more the algorithm uses the individual's data (Sawtooth Software Inc., 2009). The importance of each attribute is then calculated from the scale of difference in utilities. For a simple example of how the importance is calculated, consider the following respondent's response to patch conditions:

\begin{tabular}{llll} 
Sea State & Utility & Distance from Port & Utility \\
\hline Rough & 0 & 10 miles away & 60 \\
Moderate & 20 & 20 miles away & 20 \\
Calm & 70 & 30 miles away & 10 \\
\hline Range of utilities & 70 & & 50
\end{tabular}

The importance of each attribute (sea state and distance to port) as a percentage is calculated as:

Importance of attribute $=$ range of utilities for that attribute $/$ sum of ranges across all attributes 
Therefore in this example:

Importance of sea state $=(70-0) /(70+50)=0.58$

Importance of distance to port $=(60-10) /(70+50)=0.42$

Sea state would be considered more important than distance from port for patch choice in this case. We can also predict how fishers might choose between patches. This respondent should prefer a calm patch at a distance of 30 miles away from port (total utility 80 ) over a moderate patch at a distance of 20 miles away from port (total utility 40). The same respondent should be indifferent to a choice between a moderate patch 10 miles away, and a calm patch 30 miles away (both total utility of 80 ).

A principal components analysis (PCA) was used to identify the similarity among the different strategies adopted by each individual fisher in relation to patch choice. The strategy of an individual fisher was described by the importance scores for each patch attribute in the conjoint analysis. As there were six attributes, each fisher's strategy was described by their importance scores for each of the six attributes. The first three principal components accounted for $88 \%$ of the variance in the importance scores. The data were standardised and then a similarity matrix was calculated from the conjoint importance scores for all fishers, using Euclidean Distance. A cluster analysis was then used to identify whether fishers could be grouped by the similarity in their responses in the conjoint analysis, i.e. fishers who placed similar importance on each patch attribute.

Having identified different groupings of fishers based on the cluster analysis of the conjoint importance scores, we then explored whether the similarities in strategy within each grouping of fishers were supported by each individual's corresponding questionnaire responses, and in the trips and catches recorded in those fishers' VMS and logbook data. A Kruskal-Wallis test, with Dunn's post hoc testing adjusted for ties, was used to compare the questionnaire survey responses among fishers, with the cluster set as the factor (Kruskal and Wallis, 1952). General or generalised linear models (GLMs, Nelder and Wedderburn, 1972) were used to explore differences in logbook variables recorded by vessels in each of the behavioural groupings, with the logbook variable as the response, and the cluster as the explanatory factor (see Table 4 for list of significant logbook variables). Akaike's Information Criterion (AIC) was used to select the best model fit between a Gaussian or Gamma family for each variable tested (Akaike, 1973).

Relating trip characteristics to the clusters provided context within which to understand more about each of the different behavioural strategies adopted by fishers. E.g. If fishers that placed the highest importance on roe status (i.e. valuable product) were also the fishers who 
had the highest value per unit fuel, we could conclude that these fishers are successfully targeting a high quality product. This comparison of the conjoint analysis and questionnaire data with the individuals' VMS and logbook data allowed verification of the questionnaire responses, as well as the behavioural patterns identified in the conjoint analysis. We could determine to what extent the behavioural strategies identified in the cluster analysis were reflected in the catch records of those fishers. In addition, we could also verify the accuracy of the behavioural parameters provided during the questionnaire (e.g. minimum viable catch, distance travelled) by comparing them to those derived from logbook data. The PCA and cluster analysis were performed in PRIMER (v.6) (Clarke and Gorley, 2006), all other statistical analyses were performed in R Version 3.1.2 (R Core Team, 2016). 


\section{Results}

A total of 14 conjoint analysis responses were available for analysis. The sample size represented $56 \%$ of the 25 active IOM scallop vessels. Vessels ranged from $9.9 \mathrm{~m}$ to $16 \mathrm{~m}$ in length. Despite a slight skew towards larger vessels, the vessels surveyed were representative of the IOM fleet by length (Figure. 1, Welch's $F(3,29.85)=0.73, p=0.17$ ). The questionnaire is thus representative of the inshore IOM fishery, but may not be representative of the wider UK fleet as it fails to account for the larger vessels, despite displaying a borderline non-significant difference in lengths (Welch's $F(3,32.216)=1.88, p=$ 0.07). The maximum number of dredges used by each vessel ranged from 4 to 8 per side. Respondents had a range of fishing experience, from 3 to 62 years fishing. Six fishers owned their own vessels, and had been vessel owners from 8 months to 31 years.

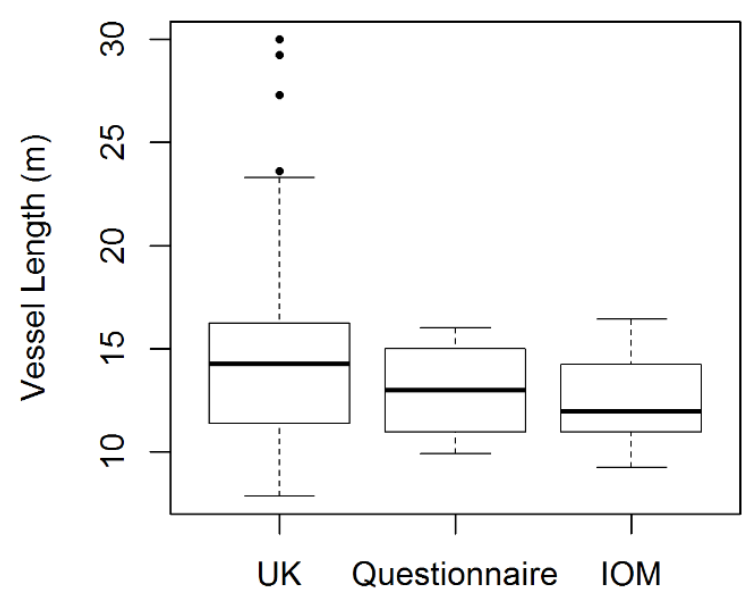

Figure 1 Lengths of vessels fishing in ICES square 36E5 and 37E5 between 2008 and 2014. "UK" refers to all UK scallop vessels recorded in the logbook data, "IOM" refers to all Isle of Man scallop vessels in the logbook data, and "Questionnaire" refers to the population of IOM scallop vessels included in the questionnaire survey.

3.1. Questionnaire responses provided foraging parameters relevant to parameterising a fisheries behavioural model

Questionnaire behavioural response values (i.e. questions concerning fishing activity) were compared with the demographic variables and vessel characteristics to identify heterogeneity in behavioural and energetics rules. Responses were compared with vessel length and vessel capacity units $\left(\mathrm{VCU}, \mathrm{VCU}=(\right.$ length * beam $)+\left(\right.$ engine power $\left.(\mathrm{kW}){ }^{*} 0.45\right)$, Pascoe and Gréboval, 2003), to construct size based rules that could account for the 
variability in ability and requirements of different sized vessels in a model. VCU had a stronger correlation with many variables than vessel length, suggesting that VCU may be a better metric when defining different behaviours for different categories of vessels (Appendix 1). Average number of crew, maximum number of dredges used, fuel use, what might be considered as good takings, storage space, and fishing costs for a day of fishing were all significantly correlated with VCU with $\mathrm{R}^{2}$ values all > 0.6 (Figure 2, Appendix 1). However, if the single point for a large vessel is removed the correlation coefficients fall to 0.79 for average crew, 0.80 for max dredges, 0.74 for fuel use, 0.58 for good takings, 0.53 for max bags stored, and the costs per day are no longer significantly correlated. Further data collection for larger vessels would provide more insight into these patterns.
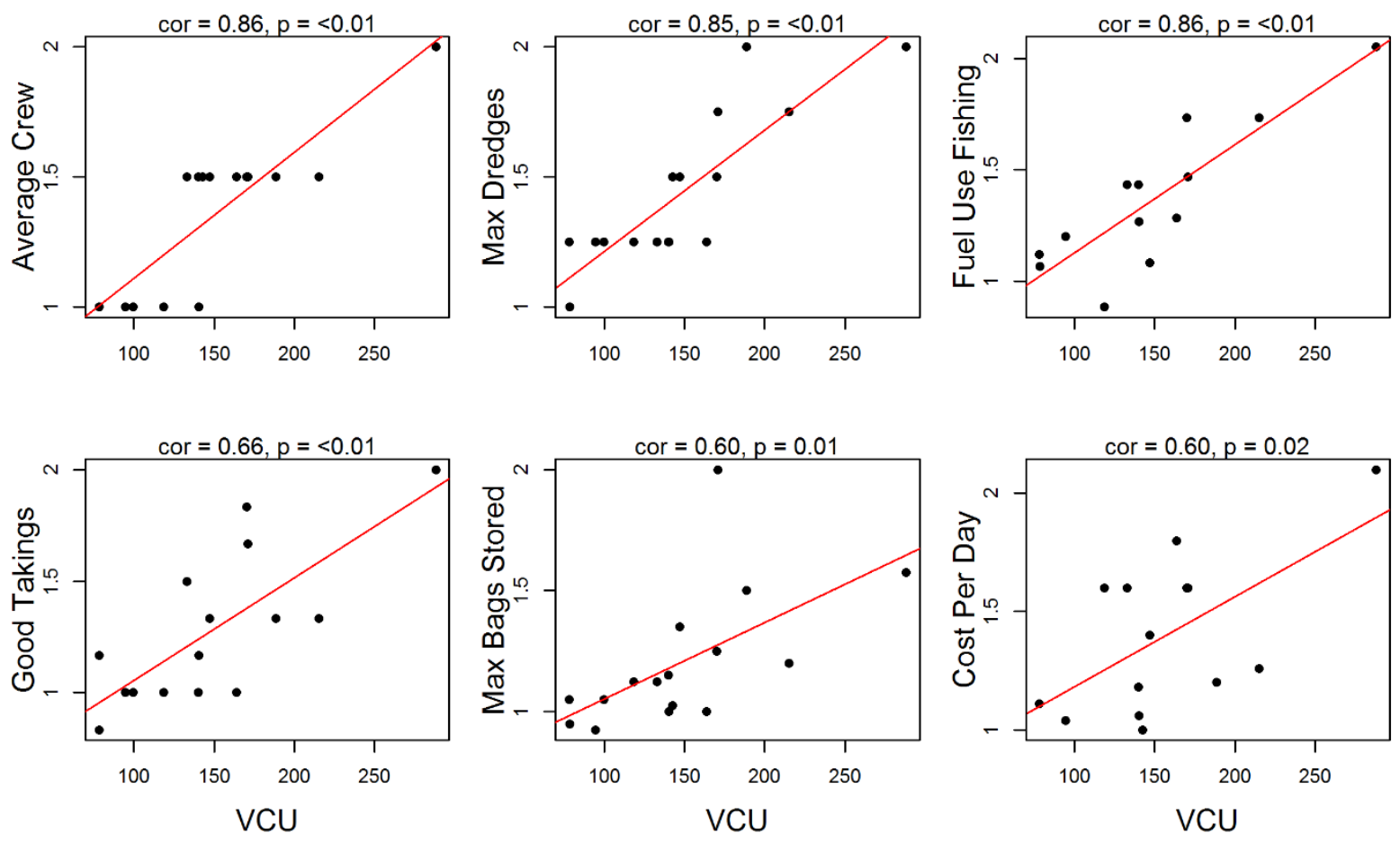

Figure 2: Pearson correlation between vessel characteristics collected from the questionnaire and the size of the vessel (VCU). Values on the $y$ axis are presented as a scaled response for confidentiality.

3.2. Conjoint analysis increased our understanding of fishing decisions that drive patch choice behaviour.

The conjoint analysis demonstrated that sea state was the most important attribute that influenced the choice of fishing patch (Table 2). This was followed by distance to port, and 
then tow quality. Meat quality, roe status and cobble were relatively similar, but of lower importance.

Table 2. Importance of each patch attribute, and the utility score of each attribute level in the conjoint analysis.

\begin{tabular}{|c|c|c|c|c|c|}
\hline \multirow[t]{2}{*}{ Attribute } & \multicolumn{2}{|c|}{ Attribute Importance } & \multirow[t]{2}{*}{ Attribute Levels } & \multicolumn{2}{|c|}{ Utility Score } \\
\hline & Mean & $\begin{array}{l}\text { Standard } \\
\text { Deviation }\end{array}$ & & Mean & $\begin{array}{l}\text { Standard } \\
\text { Deviation }\end{array}$ \\
\hline \multirow[t]{6}{*}{ Sea State } & \multirow[t]{6}{*}{34.92} & \multirow[t]{6}{*}{13.71} & Calm & 100.92 & 38.48 \\
\hline & & & Slight & 92.47 & 40.83 \\
\hline & & & Moderate & 75.66 & 37.50 \\
\hline & & & Rough & -54.40 & 25.92 \\
\hline & & & Very rough & -106.06 & 44.74 \\
\hline & & & High & -108.60 & 44.08 \\
\hline \multirow{6}{*}{$\begin{array}{l}\text { Distance to } \\
\text { port }\end{array}$} & \multirow[t]{6}{*}{24.43} & \multirow[t]{6}{*}{8.09} & $5 \mathrm{mn}$ & 59.58 & 15.43 \\
\hline & & & $10 \mathrm{~nm}$ & 38.09 & 13.51 \\
\hline & & & $20 \mathrm{~nm}$ & 24.58 & 13.67 \\
\hline & & & $30 \mathrm{~nm}$ & 4.81 & 13.03 \\
\hline & & & $50 \mathrm{~nm}$ & -34.03 & 24.57 \\
\hline & & & 80nm & -93.03 & 42.35 \\
\hline \multirow[t]{3}{*}{ Tow quality } & \multirow[t]{3}{*}{17.00} & \multirow[t]{3}{*}{6.82} & Low & -59.79 & 25.16 \\
\hline & & & Average & 17.56 & 13.73 \\
\hline & & & High & 42.22 & 17.26 \\
\hline \multirow[t]{6}{*}{ Cobble } & \multirow[t]{6}{*}{8.14} & \multirow[t]{6}{*}{2.36} & $1 \%$ & 25.99 & 5.87 \\
\hline & & & $10 \%$ & 13.23 & 3.56 \\
\hline & & & $20 \%$ & 3.83 & 2.41 \\
\hline & & & $30 \%$ & -5.38 & 2.47 \\
\hline & & & $50 \%$ & -14.39 & 4.02 \\
\hline & & & $80 \%$ & -22.83 & 8.93 \\
\hline \multirow[t]{2}{*}{ Roe Status } & \multirow[t]{2}{*}{7.44} & \multirow[t]{2}{*}{6.14} & Roe empty & 22.32 & 18.42 \\
\hline & & & Roe full & -22.32 & 18.42 \\
\hline \multirow[t]{3}{*}{ Meat quality } & \multirow[t]{3}{*}{7.07} & \multirow[t]{3}{*}{1.56} & Low $(12 \%)$ & -14.27 & 6.21 \\
\hline & & & Average (16\%) & -13.86 & 3.09 \\
\hline & & & High (20\%) & 28.13 & 3.14 \\
\hline
\end{tabular}

The software calculated utility scores for each level of each attribute for each individual, depending on how they responded to the patches presented to them, e.g. rough sea state has a negative utility score therefore it was having a negative influence on a fisher's likelihood of choosing a patch. Individual attribute level utility curves were derived from the results of the conjoint analysis (Figure 3). Relatively consistent thresholds can be seen at the point on the graph where each attribute changes from a positive to a negative utility (Figure 3). For example, sea state changed from a positive to negative utility score between moderate and rough for all vessels. The percentage of cobble also had a relatively 
consistent threshold of around $25 \%$ cobble in the catch. A poor tow quality has a negative utility, while both a poor and an average meat quality have a negative utility. The threshold is less clear for the distance to port, which indicated that there was more heterogeneity among fishers for this attribute. Some fishers show a negative utility score at $30 \mathrm{~nm}$ away from port, whereas other fishers were tolerant of a distance up to $50 \mathrm{~nm}$. The response to roe status was also heterogeneous, such that some fishers had a steep change in utility between empty roe and full roe, while other fishers had very little difference between the utility of empty and full roe. The latter may be driven by the specific market for which the scallops are destined.
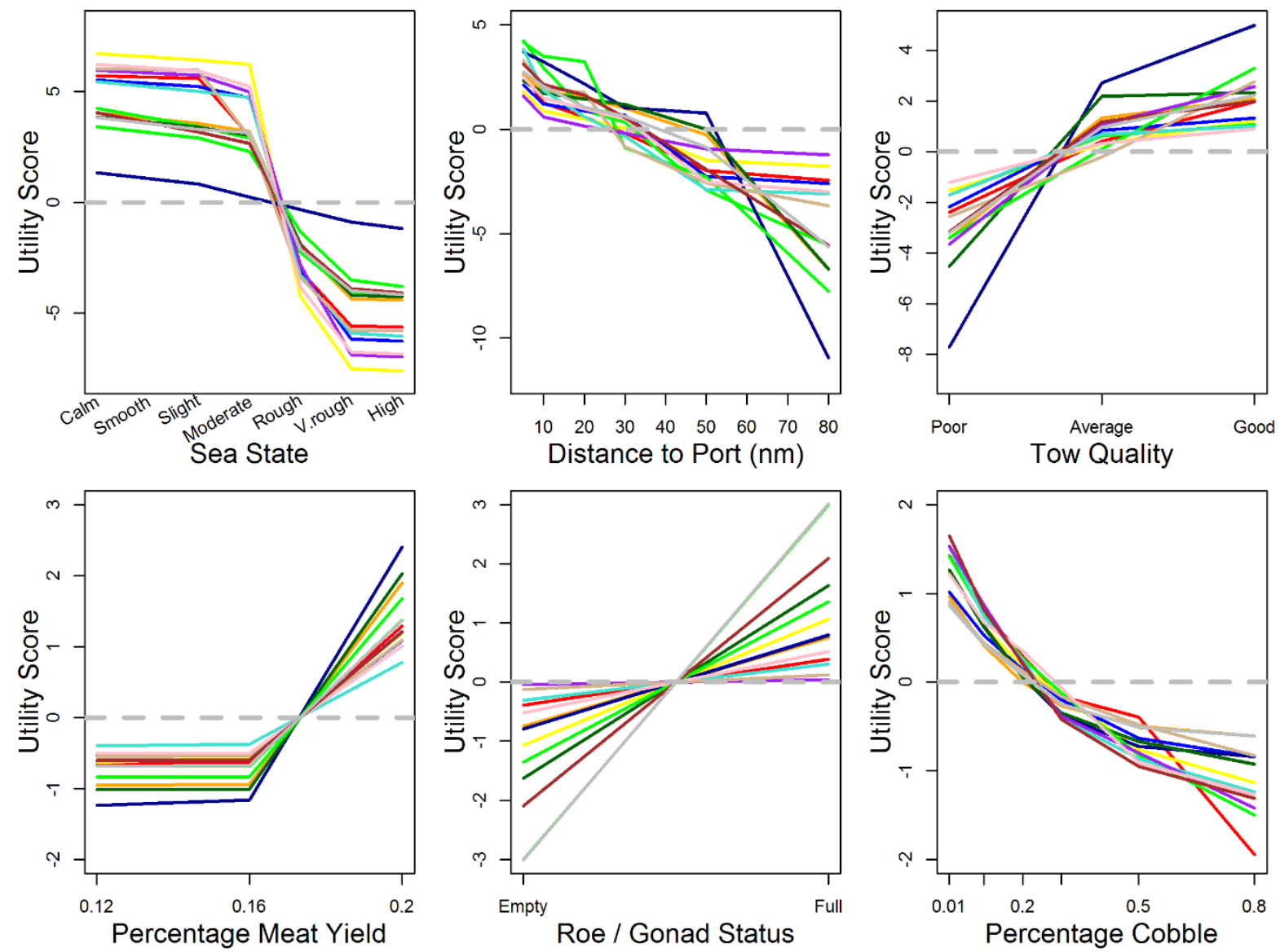

Figure 3. Individual fishers' utility scores for each attribute in the patch choice conjoint analysis, completed during interviews with fishers from the Isle of Man scallop fishery. Note that the $y$-axes differ among the graphs.

3.3. Heterogeneity in conjoint responses could be used to categorise fishers into different behavioural groups. 
The PCA on the individual importance scores revealed that there were clearly demarcated individual strategies in relation to how patch choice is made (Figure 4). The first three principal components accounted for $88 \%$ of the variance in the importance scores. PC1 was related to a higher importance of sea state and cobble, and a lower importance of distance to port, tow quality, meat yield, and roe status. PC2 was related to a higher importance of distance to port and roe status, and a lower importance of sea state, tow quality and meat yield. PC3 related to a higher importance of sea state, tow quality, meat yield and roe status, but a lower importance of distance to port and cobble. These multivariate patterns in importance scores provide insight into the different fishing strategies.

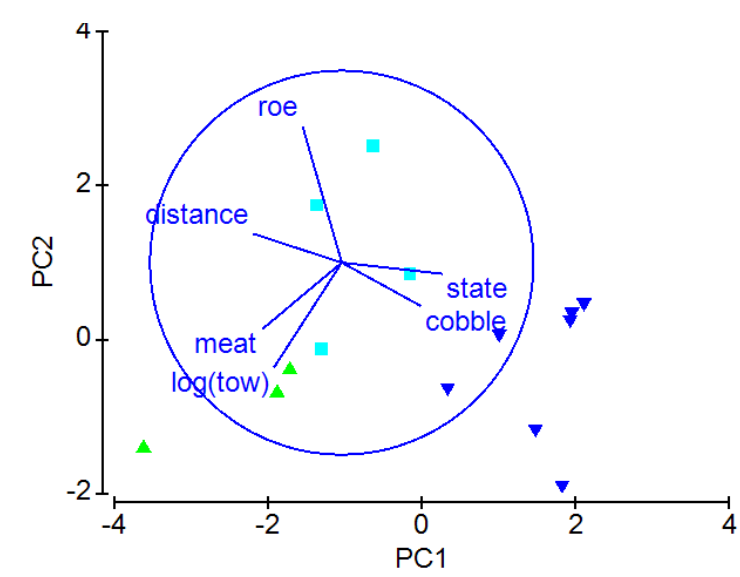

Figure 4 Principal component biplot showing the multivariate differences in each individual's perceived importance of each patch attribute in the conjoint analysis. Dark blue triangles relate to fisherss later classified as cluster 1 , green triangles relate to fishers in cluster 2 , and light blue squares relate to fishers in cluster 3 .

The importance of sea state, cobble and distance to port distinguished cluster 1 ( 7 fishers) from the other two clusters, tow quality and meat yield distinguished cluster 2 ( 3 fishers), and roe status distinguished cluster 3 (4 fishers) from the other clusters (Figure 5). The three clusters of fishers could be considered as having three different strategies for patch choice, such that each strategy was characterised by the discriminating attributes. 

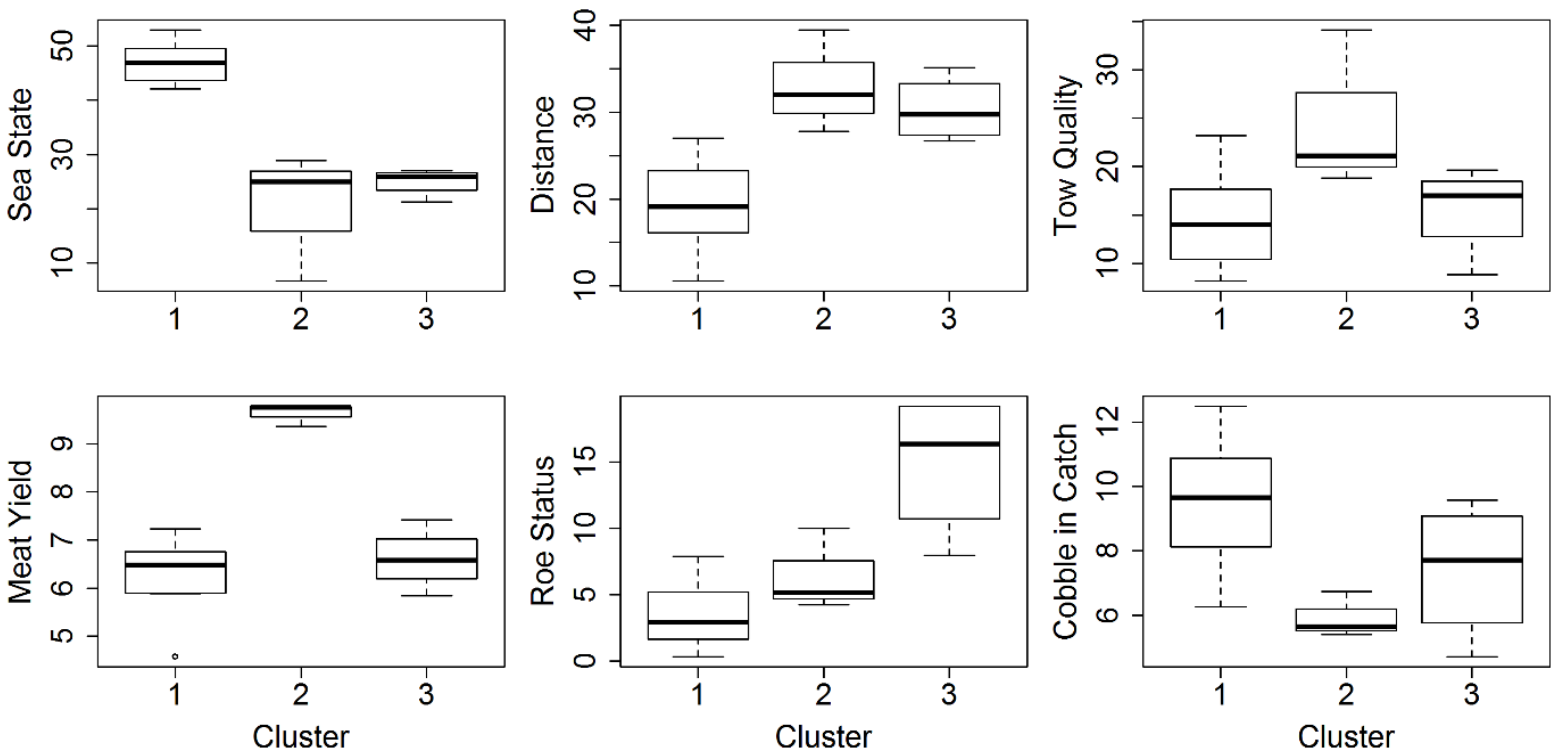

Figure 5. Importance scores for each patch attribute in the conjoint analysis, grouped according to each strategy identified in the cluster analysis. The boxplots display the minimum, $1^{\text {st }}$ quartile, median, $3^{\text {rd }}$ quartile, and maximum values.

3.4. Questionnaire responses were used to link vessel characteristics to the behavioural clusters, to understand the types of vessels that form each group.

Variables that showed a significant difference between the clusters are presented in Table 3. VCUs and vessel length differed significantly between clusters 2 and 3, with cluster 2 representing the largest vessels. There was no significant size difference between cluster 1 and 2, but all size based characteristics (VCU, length, tonnage) were lower in cluster 1, and VCU showed a trend towards significance $(p=0.08)$. Size could therefore be considered as an indicator of different behavioural strategies. Fishers in cluster 2 were the largest vessels, travelled fastest, and used the most fuel. Fishers in cluster 1 were mid-sized vessels, although not significantly different to cluster 2 . Fishers in cluster 3 were the smallest vessels, had the lowest VCU, and had the lowest economic requirements.

Table 3. Kruskal-Wallis results to determine significant differences in vessel characteristics and behaviours recorded in the questionnaire interview, between behavioural strategy clusters identified in the conjoint analysis. Dunn's post hoc testing reveals the differences between groups. Degrees of freedom vary where some fishers did not provide a response to 
a question. Dark green is statistically significant at $p=0.05$, light green is significant at $\mathrm{p}=0.1$.

\begin{tabular}{|c|c|c|c|c|c|c|c|c|c|}
\hline \multirow{2}{*}{$\begin{array}{l}\text { Questionnaire } \\
\text { Variable }\end{array}$} & \multirow[b]{2}{*}{ DF } & \multirow[b]{2}{*}{ K-W Chi-sq } & \multirow[b]{2}{*}{$\mathbf{P}$} & \multicolumn{3}{|c|}{ Median per cluster } & \multicolumn{3}{|c|}{ Dunn's $p$ value } \\
\hline & & & & 1 & 2 & 3 & $2-1$ & $3-1$ & $2-3$ \\
\hline VCU & 2,11 & 6.44 & 0.04 & 147 & 215 & 129 & 0.08 & 0.247 & 0.011 \\
\hline Vessel length & 2,11 & 6.51 & 0.04 & 14.6 & 15 & 10.9 & 0.159 & 0.123 & 0.011 \\
\hline Tonnage & 2,7 & 6.79 & 0.03 & 27 & 40 & 14.8 & 0.083 & 0.311 & 0.01 \\
\hline Average Crew & 2,11 & 6.23 & 0.04 & 3 & 3 & 2 & 0.287 & 0.075 & 0.015 \\
\hline Max Steaming ${ }^{1}$ & 2,11 & 6.05 & 0.048 & 8.5 & 9.5 & 8.1 & 0.018 & 0.863 & 0.045 \\
\hline Fuel per fishing hour & 2,8 & 7.54 & 0.02 & 23 & 32 & 16 & 0.068 & 0.223 & 0.007 \\
\hline Min Viable Gross ${ }^{2}$ & 2,11 & 7.31 & 0.026 & 900 & 1000 & 500 & 0.139 & 0.086 & 0.007 \\
\hline
\end{tabular}

\footnotetext{
${ }^{1}$ Max steaming refers to the maximum speed that a vessel can steam at.
}

${ }^{2}$ Min Viable Gross refers to the minimum catch value per day that a fisher considers economically viable.

3.5. VMS and logbook data were linked to conjoint data to determine if modelled groupings related to differences in observed behaviours.

Cluster 2 fishers recorded trips that were characterised by significantly higher departure distances, landings, duration, fuel use, and profit compared to the fishers in the other clusters (Table 4). However these fishers also recorded the lowest landed value of scallops per unit of fuel used (value per unit fuel - VPUF); they are thus catching the most, but most inefficiently. Cluster 1 fishers spent the least time at sea, travelled the least distance, but still achieved the highest catch per unit effort (CPUE), profit per unit effort (PPUE), and VPUF. Cluster 2 showed the highest profit, but cluster 1 showed the highest catch rates and value per unit effort, suggesting that cluster 1 fishers were operating in a more efficient way. Fishers in cluster 3 recorded similar (or higher) CPUE values than cluster 2, but they stayed at sea for significantly less time, and recorded lower profits, nevertheless at a significantly higher VPUF. Cluster 3 fishers display a low CPUE and landings, but at a high VPUF, suggesting they either obtain a better price for their landings or run at lower costs.

These patterns in logbook records match some of the patterns identified in the conjoint analysis; for example cluster 2 fishers placed the highest importance on tow and meat quantity, and these were the fishers that caught the most. Cluster 3 fishers caught less and stayed at sea for less time, despite potentially having the ability to catch more (i.e. they achieved CPUE similar to cluster 2), but their VPUF was significantly higher, which could be consistent with their strategy identified in the conjoint analysis of targeting a higher quality product. Cluster 1 fishers recorded average catches, but at the highest CPUE, PPUE and VPUF. This is perhaps consistent with their conjoint analysis cluster, in which they placed a 
higher importance on the sea state and amount of cobble they would catch, i.e. they focussed more on attributes that influence the ease and efficiency of fishing rather than those directly affecting catches. 
Table 4. GLM results to determine significant differences in logbook records between behavioural strategy clusters as identified in the conjoint analysis. Degrees of freedom vary where it was not possible to calculate a value in a logbook entry. PPUE = Profit per unit of effort.

\begin{tabular}{|c|c|c|c|c|c|c|c|c|c|c|c|c|c|}
\hline \multirow[b]{2}{*}{ Logbook Variable } & \multirow[b]{2}{*}{ DF } & \multirow[b]{2}{*}{$\mathbf{F}$} & \multirow[b]{2}{*}{ R-sq } & \multirow[b]{2}{*}{$\mathbf{P}$} & \multicolumn{3}{|c|}{$\begin{array}{c}\text { Mean value per } \\
\text { cluster }\end{array}$} & \multicolumn{2}{|c|}{$2-1$} & \multicolumn{2}{|c|}{ 3-1 } & \multicolumn{2}{|c|}{$3-2$} \\
\hline & & & & & 1 & 2 & 3 & $\mathrm{t}$ & $p$ & $\mathrm{t}$ & $p$ & $\mathrm{t}$ & $p$ \\
\hline Departure Distance & 2,2167 & $1.47 \mathrm{e}^{5}$ & 0.99 & $<0.001$ & 10.5 & 11.3 & 11.8 & 3.11 & 0.002 & 3.8 & $<0.001$ & 1.0 & 0.30 \\
\hline Scallop Value & 2,2157 & $8.76 \mathrm{e}^{13}$ & 1 & $<0.001$ & 1187 & 1401 & 1118 & 7.24 & $<0.001$ & -2.0 & 0.041 & -6.5 & $<0.001$ \\
\hline Hours at sea & 2,2170 & 295 & 0.21 & $<0.001$ & 19.2 & 23.7 & 21.2 & -23.9 & $<0.001$ & -9.0 & $<0.001$ & 9.2 & $<0.001$ \\
\hline Fuel Used & 2,2170 & $3.8 e^{12}$ & 1 & $<0.001$ & 220 & 374 & 212 & 31.9 & $<0.001$ & -1.7 & 0.098 & -19.8 & $<0.001$ \\
\hline CPUE (per tow ${ }^{1}$ hours) & 2,2170 & $5.5 e^{8}$ & 1 & $<0.001$ & 103.9 & 98.36 & 95.1 & -2.19 & 0.029 & -2.88 & 0.004 & -0.99 & 0.32 \\
\hline CPUE (per active ${ }^{2}$ hours) & 2,2158 & $6.6 e^{8}$ & 1 & $<0.001$ & 77.8 & 68.3 & 68.5 & -5.76 & $<0.001$ & -4.61 & $<0.001$ & 0.08 & 0.93 \\
\hline Profit & 2,2157 & 13.04 & 0.01 & $<0.001$ & 1046 & 1165 & 982 & -4.25 & $<0.001$ & 1.89 & 0.059 & 4.66 & $<0.001$ \\
\hline PPUE (per active hours) & 2,2157 & 27.47 & 0.02 & $<0.001$ & 113.6 & 95.0 & 100.3 & 6.90 & $<0.001$ & 4.08 & $<0.001$ & -1.38 & 0.168 \\
\hline PPUE (per tow hours) & 2,2157 & 11.29 & 0.01 & $<0.001$ & 150.4 & 133.4 & 138.3 & 4.43 & $<0.001$ & 2.60 & 0.009 & -0.91 & 0.37 \\
\hline Wind speed & 2,2170 & $1.80 e^{5}$ & 0.99 & $<0.001$ & 18.5 & 19.2 & 18.8 & 1.68 & 0.093 & 0.503 & 0.62 & -0.75 & 0.454 \\
\hline VPUF & 2,2157 & $6.04 e^{4}$ & 0.98 & $<0.001$ & 5.63 & 3.76 & 5.34 & -16.39 & $<0.001$ & -1.99 & 0.047 & 11.6 & $<0.001$ \\
\hline CPUE (per dredge hour) & 2,2170 & $2.16 \mathrm{e}^{6}$ & 0.99 & $<0.001$ & 17.5 & 14.3 & 16.7 & -8.31 & $<0.001$ & -1.58 & 0.114 & 4.93 & $<0.001$ \\
\hline
\end{tabular}

${ }^{1}$ tow hours $=$ time spent towing

${ }^{2}$ active hours $=$ time spent towing + time spent steaming 
3.6. By comparing the differences in the data types, three behavioural strategies have been identified.

By comparing the differences in the conjoint analysis, questionnaire responses, and logbook entries, three behavioural strategies can be identified; fishers with larger more powerful vessels that are most concerned with maximising the quantity and meat quality of catches (cluster 2 - quantity maximisers); efficient fishers with mid-sizes vessels who place a higher than average importance of sea state and amount of cobble when deciding where to fish (cluster 1 - efficient fishers); and smaller, less powerful, potentially less economically driven fishers, who place a higher than average importance of roe on scallops (cluster 3 - quality maximisers).

Table 5. Description of behavioural strategies determined from the conjoint analysis, questionnaire responses, and VMS and logbook data.

\begin{tabular}{|c|c|c|c|}
\hline & Cluster 1 & Cluster 2 & Cluster 3 \\
\hline $\begin{array}{l}\text { Conjoint } \\
\text { analysis }\end{array}$ & $\begin{array}{l}\text { Higher than average } \\
\text { importance of sea state and } \\
\text { cobble habitats }\end{array}$ & $\begin{array}{l}\text { Higher than average } \\
\text { importance of tow quality and } \\
\text { meat yield. }\end{array}$ & $\begin{array}{l}\text { Higher than average } \\
\text { importance of roe on scallop }\end{array}$ \\
\hline $\begin{array}{l}\text { Questionnaire } \\
\text { data }\end{array}$ & $\begin{array}{l}\text { Smaller vessels than cluster } \\
2 \text {, but not statistically } \\
\text { significantly smaller than } \\
\text { cluster } 3 \text { vessels. Same } \\
\text { gross requirements as } \\
\text { cluster } 2 \text {, but significantly } \\
\text { lower steaming speed and } \\
\text { lower fuel use. }\end{array}$ & $\begin{array}{l}\text { Largest vessels (by VCU), } \\
\text { which travelled fastest, and } \\
\text { used the most fuel. }\end{array}$ & $\begin{array}{l}\text { Smallest vessels, with lowest } \\
\text { tonnage, and crew members. } \\
\text { Lowest economic targets. }\end{array}$ \\
\hline $\begin{array}{l}\text { VMS and } \\
\text { logbook data }\end{array}$ & $\begin{array}{l}\text { Average catch values, but } \\
\text { travel least distance and } \\
\text { have highest CPUE, PPUE, } \\
\text { VPUF, and CPUE }\end{array}$ & $\begin{array}{l}\text { High distances travelled, } \\
\text { value landed, trip duration, } \\
\text { fuel used, and profit, but with } \\
\text { lowest VPUF and } \\
\text { CPUE }_{\text {perdredge. }}\end{array}$ & $\begin{array}{l}\text { Least time at sea, lowest } \\
\text { value of scallops landed and } \\
\text { lowest profit - but at a higher } \\
\text { VPUF than cluster } 2 \text {. }\end{array}$ \\
\hline $\begin{array}{l}\text { Description of } \\
\text { behavioural } \\
\text { strategy }\end{array}$ & $\begin{array}{l}\text { Large vessels with mid-range } \\
\text { power (VCU), who consider } \\
\text { more external patch } \\
\text { variables such as sea state, } \\
\text { cobble and distance to port, } \\
\text { rather than purely the catch } \\
\text { rates. Attain the best catch } \\
\text { rates, fishing most efficiently. }\end{array}$ & $\begin{array}{l}\text { Largest most powerful } \\
\text { vessels, potentially most } \\
\text { economically driven, } \\
\text { targeting the quantity of } \\
\text { scallops and the meat yield, } \\
\text { i.e. aiming for a large volume } \\
\text { catch, with high meat } \\
\text { content. }\end{array}$ & $\begin{array}{l}\text { Smaller, less powerful } \\
\text { vessels, who catch less } \\
\text { scallops and stay at sea for } \\
\text { less time, targeting a higher } \\
\text { quality product, who are } \\
\text { potentially less economically } \\
\text { driven. }\end{array}$ \\
\hline $\begin{array}{l}\text { Number of } \\
\text { Vessels }\end{array}$ & 7 & 3 & 4 \\
\hline $\begin{array}{l}\text { Behavioural } \\
\text { Strategy }\end{array}$ & Efficient Fisher (EFF) & Quantity Maximiser (QTM) & Quality Maximiser (QLM) \\
\hline
\end{tabular}




\subsection{Comparison of Questionnaire and Conjoint Responses}

The responses given in the questionnaire interview were compared to the results derived from the conjoint analysis, to see if similar responses emerged from these two independent data sources, providing some validation of the accuracy of responses. During the questionnaire fishers were asked what the maximum sea state was that would prevent them from fishing. The responses given are indicated as a red histogram on the plot of the utility scores (Figure 6a). There is a consistent agreement between where the sea state utility begins to fall and where it reaches its minimum utility with the range of values provided during the interviews. This provides confidence that we have successfully identified the range of sea states which begin to hinder fishing activity. The response to distance to port is not quite as clear cut as the response to sea state. The questionnaire responses for maximum distance to port (red histogram) appear to be at the lower end of the values identified in the conjoint analysis (Figure 6b). Figure $6 c$ shows the overlap between distances from port observed in the VMS data (histogram), and the range of distances identified in the questionnaire (red) and conjoint analysis (blue). The conjoint analysis appears to have better identified the distances at which the trip frequencies decline. The range of maximum distances from the questionnaire survey overlap a larger proportion of observed trip distances, which could suggest some fishers have underestimated the distances they travel, or could reflect individual heterogeneity in responses.
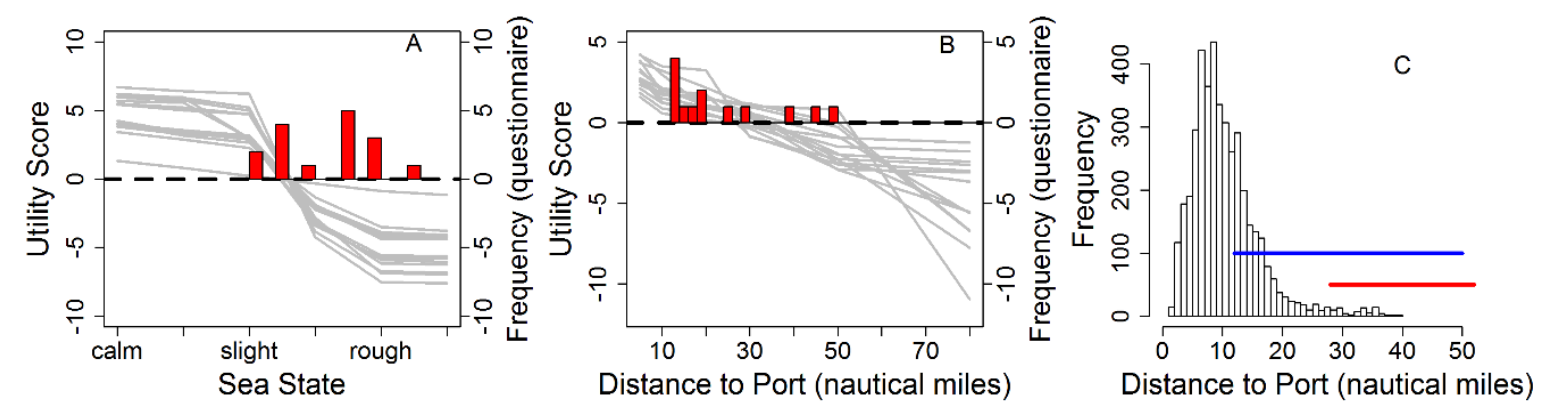

Figure 6. Conjoint utility scores for sea state (A) and distance to port (B), with the number of questionnaire interview responses overlaid as red histograms corresponding to 'the sea state above which you would no longer fish' and the 'maximum distance you would travel from port in a fishing trip' respectively. Bars fall between sea states listed on the $x$ axis when a fisher responded with a range, e.g. force 4-5, plotted as force 4.5. C) Histogram of distance to port values derived from logbook data, with a red line indicating the range between which conjoint utility scores first fall below zero and the upper limit where all conjoint utility scores are below zero. Blue line indicates the range of distances 
identified in the questionnaire as the 'maximum distance to port' fishers would travel in a single fishing trip.

\subsection{Validation of Questionnaire and Conjoint Responses}

Both aggregated and individual responses to questions were verified against the independent VMS and logbook data. Fishers provided values for hours spent at sea, distance travelled, the catch rate at which they would move fishing ground, and the minimum viable catch value for a trip, which could be compared to the observed values in VMS data. At an aggregated level, the questionnaire responses appear to give similar responses to the logbook data for departure distances, landings, and catch rates (Figure 7). The hours at sea responses appear to slightly underestimate the actual time spent at sea, however. The accuracy of each individual's questionnaire responses was assessed by comparing them to their own VMS and logbook data (Figures 8). Boxplots display each logbook variable for each individual fisher, and their corresponding questionnaire responses were overlaid as points. If the questionnaire response (point) falls in an appropriate place in the boxplot (e.g. at the lower range of the catch value boxplot for minimum viable catch) it provides evidence of the reliability of the questionnaire responses. This validation is somewhat qualitative, as the questions were somewhat subjective and/or speculative. The individual comparison data showed that fishers fairly consistently provided a minimum viable catch value in the lower quartile of the observed value landed, and a good takings value in the upper quartile (Figure 8a). The catch rates that a fisher considered as good, average or poor appear relatively consistent with their recorded catch rates (Figure 8c). We can therefore consider the catch rates given in the questionnaire as relatively accurate. In general the values given for normal hours at sea fall within the observed trip lengths (Figure 7); the maximum possible trip length values appear quite variable, but as this is a speculative answer perhaps more variation is expected. Similarly, the departure distances given in the survey appear reasonably accurate, although slightly higher, with the more speculative maximum departure distance exhibiting more variation. 

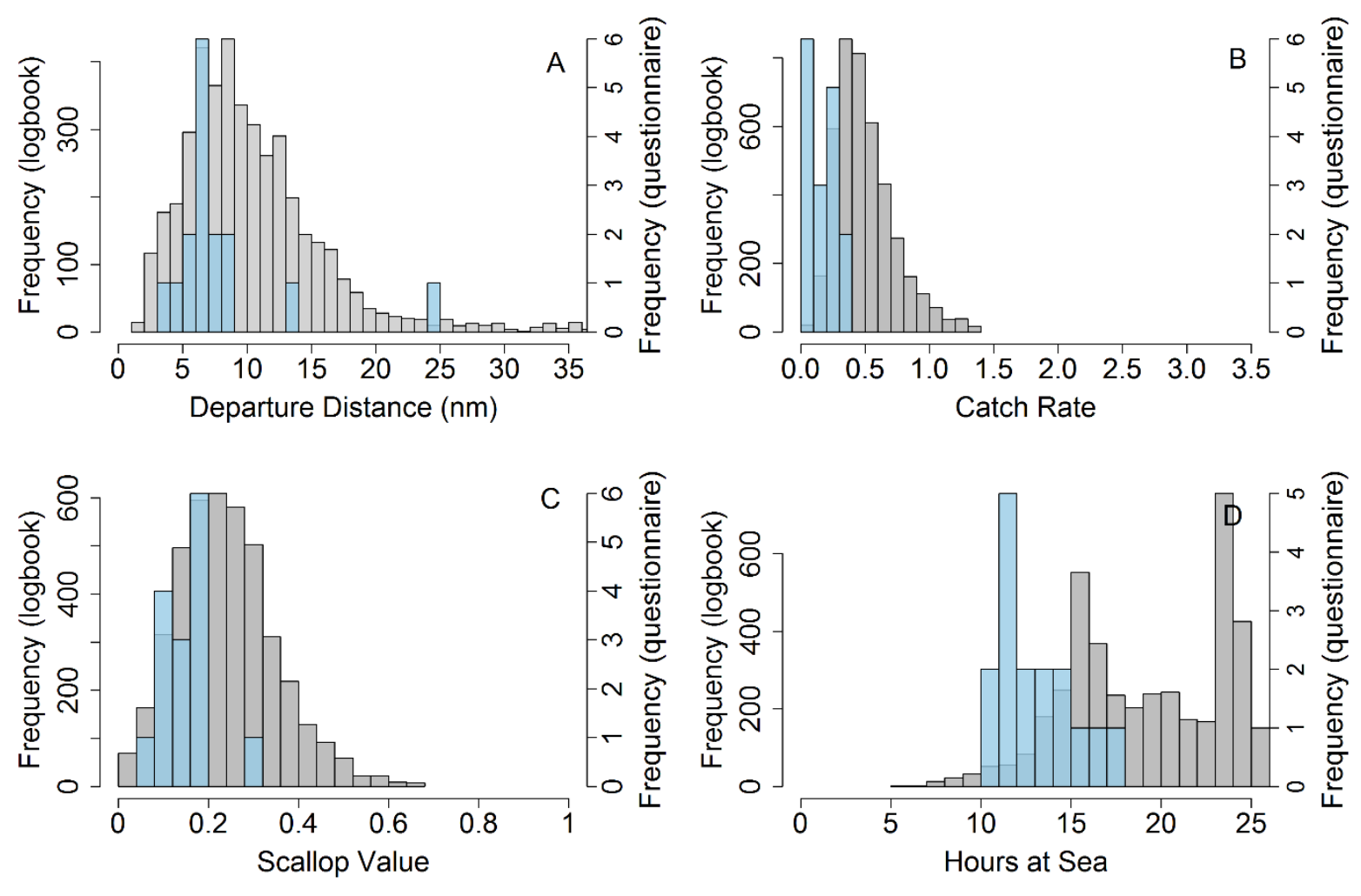

Figure 7. Grey histograms represent logbook data for all scallop logbook records from Isle of Man vessels. Blue overlaid histograms represent questionnaire data. A) Grey histogram of departure distances from VMS data, with blue histogram indicating individual answers to "What is the normal distance you would travel from your departure port to fish?' B) Grey histogram of recorded catch rates, as bags per dredge, with blue histogram indicating answers to 'At what catch rate would you change fishing location?' C) Grey histogram of the value of scallops landed per trip, and blue histogram of answers to 'What is the minimum viable catch for a trip? Values are scaled from zero to one for confidentiality. D) Grey histogram of trip length in hours at sea from VMS data, and blue histogram of answers to 'How long would you normally fish for?' 

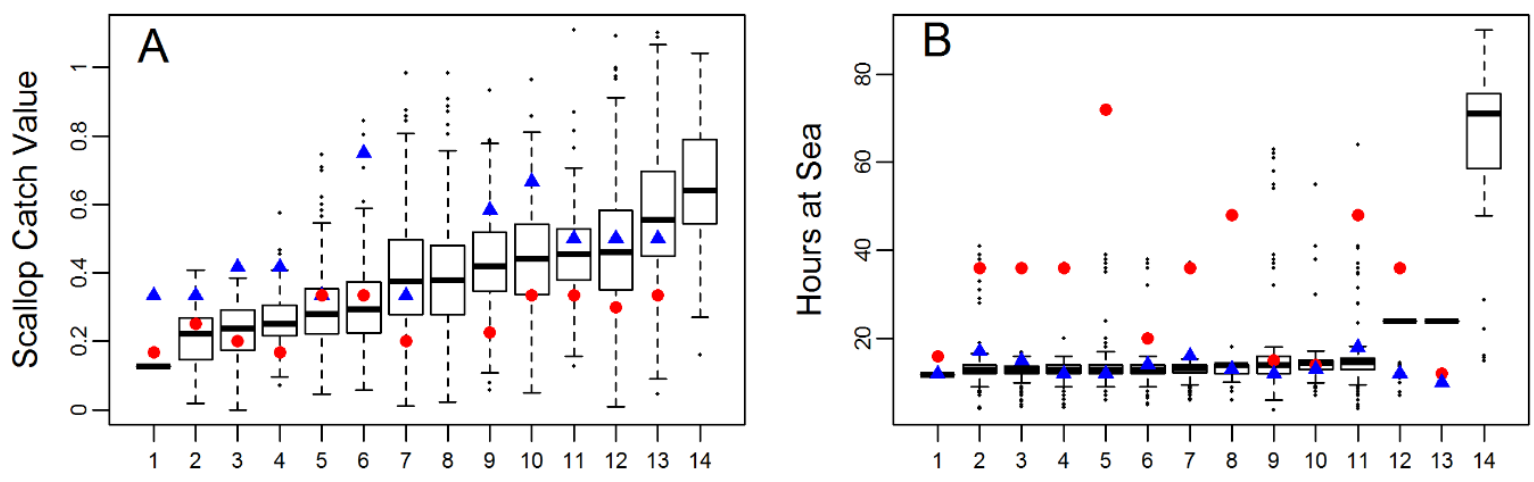

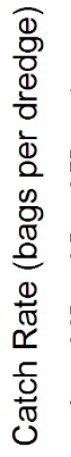
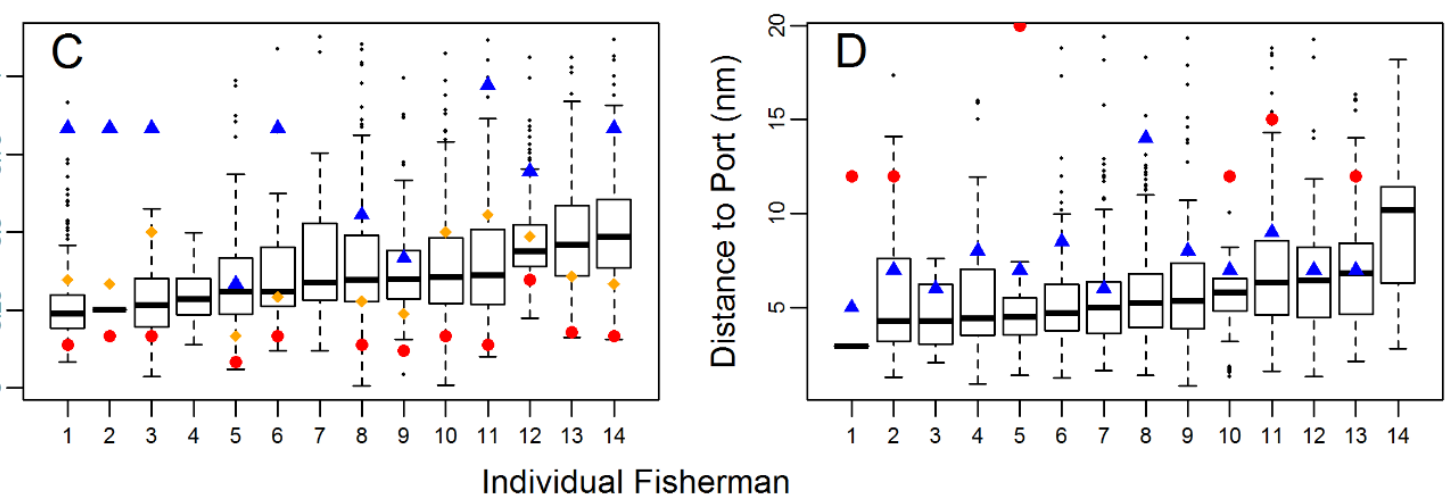

Figure 8. Verification of individual questionnaire responses with vessel monitoring system (VMS) and logbook data. Boxplots represent VMS and logbook values for each individual fisher, and coloured dots represent their corresponding questionnaire responses. The number of points vary where a fisher did not provide a response to a question. Actual values of catch value and rates are concealed for confidentiality, with a scaled response presented. $\underline{\mathbf{A}}$ ). Boxplots of observed scallop landings (monetary value, from logbooks). Red points represent answer to the question "What is your minimum viable daily catch?", and blue points represent answers to the question "What do you consider as "good takings" for a trip?" B) Boxplots of observed trip length (hours at sea, from logbook). Blue point represents "How long would you normally fish for?" and red point represents "What is the maximum

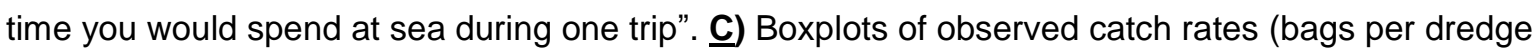
hour, from VMS), with corresponding value provided for question "What do you consider a good catch rate (blue) an average catch rate (orange) and a poor catch rate (red)?" ) Boxplots of observed departure distances (nautical miles, from VMS). Blue points represent "What distance would you normally travel from port to fish?", red points represent "What is the maximum distance from port you would travel to fish?" 


\section{Discussion}

4.1. Fishers' data can increase understanding of fishing behaviour and patch choice.

We have demonstrated that data derived directly from fishers can improve the understanding of fishing behaviour, and provide relevant and reliable data that can be used to parameterise a fisheries behavioural model. Using a conjoint analysis approach it was possible to gain a comprehensive understanding of the fishing decisions that drive patch choice and that explain the behaviours that lead to patterns in the spatial distribution of fishing effort. As Plagányi et al., (2014) pointed out, it is the human decisions of patch choice that drive the spatial distribution of effort, therefore to model a fishery realistically it is necessary to understand these decisions. For example, we have demonstrated that the sea state can have a large influence on the patch choice behaviour, therefore it may be necessary to include this in a model predicting fisher behaviour. It is also interesting to note that the term 'average' had different connotations to the respondents; an average tow quality had a positive utility score but an average meat yield had a negative utility score. Understanding these trade-off decisions is not possible with VMS data; a conjoint analysis provided a rapid, cost-effective way to understand this patch choice behaviour. It was also possible to gain insights into the degree of individual heterogeneity, which is needed for more realistic predictions of the impacts of management on fishers (Christensen and Raakjær, 2006; Gelcich et al., 2005).

The accompanying semi-structured questionnaire provided further behavioural parameters that would be relevant to modelling fishers in the context of optimal foraging theory (i.e. fishing costs, environmental limitations, vessel characteristics and requirements). These data again represented parameters that would be difficult or impossible to obtain from vessel monitoring system data. As well as collecting vessel characteristic data that were not recorded on vessel registry data, behavioural parameters such as the giving up rate (a catch rate that a fisher considers unviable and would prompt him to move to a different fishing patch), and the handling time (the time it takes to clear nets between successive tows) could be collected. Economic parameters (the equivalent of animal energetics in optimal foraging theory) could also be ascertained, including vessel costs, what a fisher considered their minimum viable catch and what they considered as good takings. These survey data significantly contribute to, and increase the scope for understanding fisher behaviour, complementing the use of VMS and logbook data. 
4.2. Considerable behavioural heterogeneity between fishers could be used to identify different fishing strategies

There was considerable behavioural heterogeneity between the fishers surveyed; vessel capacity units (a composite size metric) and vessel length were identified as predictors of this variability. As VCUs are calculated from length, and therefore correlate, only one or the other would be used for predictive modelling. Some economic variables demonstrated strong correlation with vessel size, such as fuel use, what they consider good takings, as well as vessel characteristics such as number of dredges used, and number of crew. Other variables showed no correlation with vessel size despite being linked to potential financial returns, e.g. the catch rate at which a fisher would 'give up' and move to a new location. These foraging parameters, and their heterogeneity, can be input to a model of their behaviour.

Three behavioural strategies for patch choice could be identified within the fleet by comparing the similarities and differences in conjoint analysis responses. As identified in Table 5, fishers could be categorised as either Efficient Fishers (EFF), Quantity Maximisers (QTM) or Quality Maximisers (QLM). EFF refers to fishers that are the most efficient, in that they achieve the highest CPUE (by time and per dredge), PPUE, and VPUF, by travelling least far but still receiving average catches. These fishers place a higher than average importance on the sea state and the amount of rock in the catch, and are thus maximising efficiency by avoiding unfavourable fishing patches. These EFF fishers are also perhaps minimising risks and costs associated with taking vessels into high seas or over damaging rockier habitats. QTM fishers are the largest and most powerful vessels, concerned with maximising the quantity and meat quality of catches, obtaining the highest profits, but they do so at the lowest VPUF and CPUE perdredge rates. QLM refers to fishers with the smallest vessels who target a higher quality product (i.e. roe on), who achieve a CPUE $E_{\text {perdredge }}$ equal to EFF fishers, yet land lower catches and have the lowest profit. QLM fishers have the potential to catch as much as EFF fishers (i.e. similar vessel characteristics, and achieve similar CPUE rates per dredge hour). They also obtain similar CPUE rates to QTM fishers despite their larger size. Nevertheless, they do not stay at sea as long, record lower catches, and state a significantly lower minimum viable catch rate, which could suggest the QLM fishers are less economically driven.

The identification of a group of fishers who are less economically driven, or just not as economically successful as the others, has consequences for a model based on optimal foraging theory, where individuals are modelled as rational agents (i.e. taking the course of action that will provide the highest fitness/monetary returns). Whilst optimal foraging theory 
may be an appropriate framework within which to investigate fishing behaviour, a model of fishing behaviour may need to include fishers that do not follow the assumptions of optimal foraging theory to realistically predict the activity of a whole fleet. The general principles of optimal foraging theory may hold true in a fishery - that fishers are maximising their 'fitness' - but it may be necessary to allow the model to incorporate other non-monetary aspects of this fitness such as quality of life, through a reduced propensity to maximise purely the economic returns. Modelling all individuals as true optimal foragers may thus overestimate the stock biomass removal, as well as the ability of fishers to cope with management measures. For example, during a period of stock collapse and strict management controls in the Isle of Man in 2014, the fishers demonstrated considerable heterogeneity in their plasticity in response to tough conditions. Some fishers continued to fish on seemingly unprofitable grounds, with ground familiarity and port affinity apparently overriding the seemingly more rational choice of moving to a more distant port/ground (pers. comm., Karen McHarg, Department for Environment, Food, and Agriculture, Isle of Man). There may be several reasons a fisher does not move to a more profitable ground despite having the vessel capacity to do so: i) they are unfamiliar with the grounds, which represents an economic and safety consideration; ii) they are not aware that there are better catch rates at a different area nearby; iii) they are less economically driven and would simply prefer to remain at their usual port; iv) they are not profit maximisers and instead aim for a minimum expected yield (Oostenbrugge et al., 2001; Pet-Soede et al., 2001). For an accurate model of fishing behaviour it is necessary to capture these differences in competitiveness/success, and the influences of ground familiarity, as the fishers which are seen as less economically driven may not conform to a model that assumes solely profit driven rational activity. It is unclear from the data presented here, however, if the fishers are just less successful than others, if the fishers are intentionally not as economically competitive preferring to fish in familiar areas, or if they are maximising some other benefit, such as quality of life, more highly than monetary returns. Nonetheless, to reach agreeable management solutions that ensure the economic sustainability of a fishery, it may be necessary to understand these behaviours, so that they can at least be taken into consideration in management planning.

4.3. Survey data were validated to give confidence in the accuracy of the data.

The data obtained during the questionnaire and conjoint analyses showed a good level of agreement with vessel monitoring system and logbook data, demonstrating that the fisher survey data can be considered reliable. The validation is somewhat qualitative however, as whilst quantitative responses were given, several questions were somewhat subjective (e.g. 
what do you consider as good takings?). Nevertheless, responses to similar questions in the questionnaire and the conjoint analysis showed good correlation, giving confidence that the methods were eliciting realistic values. More compellingly, the questionnaire responses also showed good correlation with corresponding VMS and logbook data, on both an aggregated and individual vessel level. The values given for departure distance appeared to be reasonable accurate, concentrated over the highest proportion of observed travel distances in the VMS data; the minimum acceptable bags per dredge hour appeared to be a very consistent and reliable value; the values for minimum viable catch were slightly skewed towards the lower end of observed catches, as you would expect if the fishery is profitable, but it does suggest a proportion of trips may be considered unviable. The hours at sea values provided by fishermen are skewed towards more negative values than the VMS and logbook data however. On an individual scale, values provided during the questionnaire showed a good level of congruence with each individual's corresponding VMS and logbook data. Overall, these data suggest that in the absence of VMS and logbook data, behavioural data of a reasonable accuracy could be obtained from fishers.

The behavioural clusters identified in the conjoint analysis could also be somewhat verified through comparing them with questionnaire and logbook data. Behavioural differences identified in the conjoint analysis translated to real differences in observed behaviours in the VMS and logbook data. For example, fishers that placed the highest importance on expected return rates and meat yield in the conjoint analysis demonstrated higher catch rates and landings in logbook data accordingly. These patterns give confidence that the conjoint analysis has successfully identified real differences in the patch choice behavioural strategies of different fishers.

There are, nevertheless, two potential types of inaccuracy relevant to this survey data: deliberate bias and unintentional inaccuracy. Economically and industry sensitive data, such as catch rates and values, are most likely known well by the fishers, but they could be wary of revealing them to scientists, and therefore deliberately bias responses. Economic parameters were shown to be of good accuracy, which could give confidence that less sensitive parameters were also accurate to the best of the fishers' knowledge. If fishers were unhappy to give any response or value, they could leave it blank, as having missing values was considered preferable to inaccurate values. It would be difficult for respondents to deliberately bias answers in the conjoint analysis, as it is not easy to quickly compute how to skew the responses to an agenda. A final source of error is misrepresentation of the fleet. Even though a relatively high proportion of the fishery was surveyed $(56 \%)$, it is likely some individual heterogeneity was missed. As we surveyed over half of the active fishers though, 
we can have some confidence that we have a fair representation of the fishery (Shepperson et al., 2014).

This survey approach to parameterising an IBM is the first step in a participatory modelling framework. Taking a more participatory approach can provide a form of mutual validation between fisher and scientist with regards to modelling fisher behaviour realistically. Scientists can be more confident they have captured the essential elements of the fishery, and have a realistic portrayal of fishing behaviour, and fishers can have more confidence that the scientists are basing their model on informed fisheries data. As described by Mackinson et al. (2011) and Röckmann et al. (2012), involving fishers in the modelling process can increase the transparency of the project and thus the trust of data and model outputs, leading to more successful management plans. Nevertheless, there does remain some scepticism among the scientific community as to whether fishers' data can be of comparable accuracy to more conventional scientific data. It is thus important to provide an assessment of data accuracy from all steps of the participatory process where possible, to ensure appropriate use of the data, and to contribute to the growing body of evidence showing that fisher knowledge and participatory data can make a valuable contribution to conventional science (Bundy and Davis, 2013; Shepperson et al., 2014; Teixeira et al., 2013; Zukowski et al., 2011).

\subsection{This approach provided data relevant to parameterising a fisheries IBM}

The data obtained in this survey are highly relevant to parameterising a fisheries behavioural model, both in terms of model design and understanding of fishing behaviour. Grouping fishers into types would allow simplification of a model design, which accounts for some heterogeneity between fishers without leading to an overly complex model design. Three behavioural strategies for patch choice were identified in the conjoint analysis, which could be specified in an IBM of fishing activity. The impact of management on different types of fishers could then be explored, as fishers may be impacted to different degrees. VCU was the best predictor of foraging parameters, behavioural strategy and vessel economics, and therefore could be used to characterise a fishery for proportional input of fishers of each behavioural strategy into a model. Characterising the fishery in this way could simplify the model design, whilst ensuring heterogeneity in fishing behaviour was accounted for.

The survey time could be considered as limitation to the approach, but these surveys were undertaken in a relaxed informal format, with fishers free to lead the discussion onto topics they felt relevant. The survey time could therefore fairly easily be reduced. Depending on the computer literacy of the fishing fleet in question, the conjoint analysis could be fielded online, 
as could the questionnaire, allowing fishers to complete the survey in their own time, and reducing the time costs to the researcher.

\section{Conclusions}

The use of conjoint analysis has demonstrated in detail how fishers assess various patch attributes such as sea state, distance to port and expected catch rates, to decide which patch they would prefer to fish in. This could have direct application to a fisheries (or other hunter-gatherer) behavioural model. Further, the data also demonstrated behavioural heterogeneity, in that either some fishers are not as economically driven, or are less successful, as they do not appear to be reaching their full catching potential, compared to other similar fishers. Individual-based models (IBMs) are increasingly recognised as potentially useful management models in fisheries (Bastardie et al., 2014, 2010; Dowling et al., 2012), but they can be data intensive, as a thorough understanding of the behavioural decisions driving a system is required. Here we have demonstrated an accurate and costeffective method to collect the necessary data required to parameterise a fisheries IBM in the context of optimal foraging theory. Using this approach could make a model more relevant to a fishery through ensuring the behavioural decision processes are realistic (Fulton et al., 2011; Hilborn, 2007). Through developing models in collaboration with fishers, we can be more confident we have a realistic and thorough understanding of the system, and can thus better predict the outcomes of management. Better, more realistic predictions of the temporal and spatial displacement of effort following management would allow the economic and ecological impacts to be better understood, ultimately leading to more successful and sustainable management. 


\section{Acknowledgements}

The authors would like to thank the Isle of Man scallop fishers for taking part in the survey and providing the data for this paper. This work forms part of a PhD studentship funded jointly by the Centre for Environment, Fisheries and Aquaculture Science (Cefas) and Bangor University. Author contributions: JS, MK, LM designed the research; JS performed the research; JS analysed the data; JS wrote the initial paper with editorial input from MK, LM, EB and SM; MK, LM, SM, EB supervised the work. 
Abernethy, K.E., Allison, E.H., Molloy, P.P., Côté, I.M., 2007. Why do fishers fish where they fish ? Using the ideal free distribution to understand the behaviour of artisanal reef fishers 1604, 15951604. doi:10.1139/F07-125

Akaike, H., 1973. Information theory as an extension of the maximum likelihood principle. B.N. Petrov, F.Csaki (Eds.), Second International Symposium on Information Theory, Akademiai Kiado, Budapest (1973), pp. $267-281$.

Alriksson, S., Öberg, T., 2008. Conjoint Analysis for Environmental Evaluation A review of methods and applications. Env Sci Pollut Res 15, 244-257.

Bastardie, F., Nielsen, J.R., Andersen, B.S., Eigaard, O.R., 2010. Effects of fishing effort allocation scenarios on energy efficiency and profitability: An individual-based model applied to Danish fisheries. Fish. Res. 106, 501-516. doi:10.1016/j.fishres.2010.09.025

Bastardie, F., Nielsen, J.R., Miethe, T., 2014. DISPLACE: a dynamic, individual-based model for spatial fishing planning and effort displacement - integrating underlying fish population models. Can. J. Fish. Aquat. Sci. 71, 1-21.

Bergmann, M., Hinz, H., Blyth, R., Kaiser, M., Rogers, S., Armstrong, M., 2004. Using knowledge from fishers and fisheries scientists to identify possible groundfish "Essential Fish Habitats." Fish. Res. 66, 373-379. doi:10.1016/j.fishres.2003.07.007

Bucaram, S.J., Hearn, A., 2014. Factors that influence the entry-exit decision and intensity of participation of fishing fleet for the Galapagos lobster fishery. Mar. Policy 43, 80-88. doi:10.1016/j.marpol.2013.05.005

Bucaram, S.J., White, J.W., Sanchirico, J.N., Wilen, J.E., 2013. Behavior of the Galapagos fishing fleet and its consequences for the design of spatial management alternatives for the red spiny lobster fishery. Ocean Coast. Manag. 78, 88-100. doi:10.1016/j.ocecoaman.2013.03.001

Bundy, A., Davis, A., 2013. Knowing in context: An exploration of the interface of marine harvesters' local ecological knowledge with ecosystem approaches to management. Mar. Policy 38, 277286. doi:10.1016/j.marpol.2012.06.003

Cabral, R.B., Geronimo, R.C., Lim, M.T., Aliño, P.M., 2010. Effect of variable fishing strategy on fisheries under changing effort and pressure: An agent-based model application. Ecol. Modell. 221, 362-369. doi:10.1016/j.ecolmodel.2009.09.019

Christensen, A.-S., Raakjær, J., 2006. Fishermen's tactical and strategic decisions. A case study of Danish demersal fisheries. Fish. Res. 81, 258-267. doi:10.1016/j.fishres.2006.06.018

Clarke, K., Gorley, R., 2006. PRIMER v6: User Manual/Tutorial. PRIMER-E, Plymouth.

Dowling, N. a, Wilcox, C., Mangel, M., Pascoe, S., 2012. Assessing opportunity and relocation costs of marine protected areas using a behavioural model of longline fleet dynamics. Fish Fish. 13, 139-157. doi:10.1111/j.1467-2979.2011.00422.x

Fulton, E. a, Smith, A.D.M., Smith, D.C., van Putten, I.E., 2011. Human behaviour: the key source of uncertainty in fisheries management. Fish Fish. 12, 2-17. doi:10.1111/j.14672979.2010.00371.x

Gelcich, S., Edwards-Jones, G., Kaiser, M.J., 2005. Importance of Attitudinal Differences among Artisanal Fishers toward Co-Management and Conservation of Marine Resources. Conserv. Biol. 19, 865-875. doi:10.1111/j.1523-1739.2005.00534.x 
Green, P., Srinivasan, V., 1990. Conjoint analysis in market research: a review of new developments. J. Mark. 54, 3-19.

Grimm, V., Railsback, S.F., 2005. Individual-Based Modeling and Ecology. Princeton University Press, Princeton.

Hadjimichael, M., Kaiser, M.J., Edwards-Jones, G., 2013. The impact of regulatory obligations on fishers' income: Identifying perceptions using a market-testing tool. Fish. Res. 137, 129-140. doi:10.1016/j.fishres.2012.09.013

Hallwass, G., Lopes, P.F.M., Juras, A. A, Silvano, R. a M., 2013. Behavioral and environmental influences on fishing rewards and the outcomes of alternative management scenarios for large tropical rivers. J. Environ. Manage. 128, 274-82. doi:10.1016/j.jenvman.2013.05.037

Hilborn, R., 2007. Managing fisheries is managing people: what has been learned? Fish Fish. 8, 285296. doi:10.1111/j.1467-2979.2007.00263_2.x

Kraak, S.B.M., Kelly, C.J., Codling, E. A, Rogan, E., 2010. On scientists' discomfort in fisheries advisory science: the example of simulation-based fisheries management-strategy evaluations. Fish Fish. 11, 119-132. doi:10.1111/j.1467-2979.2009.00352.x

Kruskal, W.H., Wallis W.A., 1952. Use of ranks in one-criterion variance analysis. Journal of the American Statistical Association 47 ( 260), 583 - 621. doi:10.1080/01621459.1952.10483441.

Lee, J., South, A.B., Jennings, S., 2010. Developing reliable, repeatable, and accessible methods to provide high-resolution estimates of fishing-effort distributions from vessel monitoring system (VMS) data. ICES J. Mar. Sci. 67, 1260 - 1271.

Mackinson, S., Wilson, D.C., Galiay, P., Deas, B., 2011. Engaging stakeholders in fisheries and marine research. Mar. Policy 35, 18 - 24. doi:10.1016/j.marpol.2010.07.003

Mackinson, S., Wilson, D.C.K., 2014. Building bridges among scientists and fishermen with participatory action research, in: Social Issues in Sustainable Fisheries Management MARE Publication Series Volume 9. pp. 121-139.

Murray, L.G., Hinz, H., Kaiser, M.J., 2011. Functional response of fishers in the Isle of Man scallop fishery. Mar. Ecol. Prog. Ser. 430, 157 - 169.

Nelder, J., Wedderburn, R., 1972. Generalized Linear Models. J. R. Statist. Soc. A 135 (3), 370 - 384.

Oostenbrugge, J. a. E. Van, Densen, W.L.T. Van, Machiels, M. A. M., 2001. Risk aversion in allocating fishing effort in a highly uncertain coastal fishery for pelagic fish, Moluccas, Indonesia. Can. J. Fish. Aquat. Sci. 58, 1683-1691. doi:10.1139/cjfas-58-8-1683

Orme, B. 2010. Getting started with conjoint analysis: Strategies for product design and pricing research. Second Edition, Madison, Wis.: Research Publishers LLC.

Pascoe, S., Gréboval, D., (eds.), 2003. Measuring capacity in fisheries. FAO Fisheries Technical Paper. No. 445. Rome, FAO. 2003. 314p.

Pet-Soede, C., Van Densen, W.L.T., Hiddink, J.G., Kuyl, S., Machiels, M. A. M., 2001. Can fishermen allocate their fishing effort in space and time on the basis of their catch rates? An example from Spermonde Archipelago, SW Sulawesi, Indonesia. Fish. Manag. Ecol. 8, 15-36. doi:10.1046/j.1365-2400.2001.00215.x

Plagányi, É.E., Punt, A.E., Hillary, R., Morello, E.B., Thébaud, O., Hutton, T., Pillans, R.D., Thorson, J.T., Fulton, E. a, Smith, A.D.M., Smith, F., Bayliss, P., Haywood, M., Lyne, V., Rothlisberg, 
P.C., 2014. Multispecies fisheries management and conservation: tactical applications using models of intermediate complexity. Fish Fish. 15, 1-22. doi:10.1111/j.1467-2979.2012.00488.x

R Core Team, 2016. R: A language and environment for statistical computing. R Foundation for Statistical Computing, Vienna, Austra. https://www.R-project.org/.

Railsback, S.F., 2001. Concepts from complex adaptive systems as a framework for individual-based modelling. Ecol. Modell. 139, 47-62. doi:10.1016/S0304-3800(01)00228-9

Reeves, S., Marchal, P., Mardle, S., Pascoe, S., Prellezo, R., Thebaud, O., Travers, M., 2009. From Fish to Fisheries: The Changing Focus of Management Advice, in: Payne, A., Cotter, J., Potter, T. (Eds.), Advances in Fisheries Science: 50 Years on from Beverton and Holt. Blackwell Publishing Ltd, Oxford, UK.

Röckmann, C., Ulrich, C., Dreyer, M., Bell, E., Borodzicz, E., Haapasaari, P., Hauge, K.H., Howell, D., Mäntyniemi, S., Miller, D., Tserpes, G., Pastoors, M., 2012. The added value of participatory modelling in fisheries management - what has been learnt? Mar. Policy 36, 1072-1085. doi:10.1016/j.marpol.2012.02.027

Ruiz-Pérez, M., Franco-Múgica, F., González, J. a., Gómez-Baggethun, E., Alberruche-Rico, M. a., 2011. An institutional analysis of the sustainability of fisheries: Insights from FishBanks simulation game. Ocean Coast. Manag. 54, 585-592. doi:10.1016/j.ocecoaman.2011.05.009

Sawtooth Software Inc., 2014. The Adaptive Choice-Based Conjoint (ACBC) Technical Paper.

Sawtooth Software Inc., 2009. The CBC/HB System for Hierarchical Bayes Estimation Version 5.0 Technical Paper.

Shepperson, J., Murray, L.G., Cook, S., Whiteley, H., Kaiser, M.J., 2014. Methodological considerations when using local knowledge to infer spatial patterns of resource exploitation in an Irish Sea fishery. Biol. Conserv. 180, 214-223. doi:10.1016/j.biocon.2014.10.013

Soulié, J.-C., Thébaud, O., 2006. Modeling fleet response in regulated fisheries: An agent-based approach. Math. Comput. Model. 44, 553-564. doi:10.1016/j.mcm.2005.02.011

Teixeira, J.B., Martins, A.S., Pinheiro, H.T., Secchin, N.A., Leão de Moura, R., Bastos, A.C., 2013. Traditional Ecological Knowledge and the mapping of benthic marine habitats. J. Environ. Manage. 115, 241-50. doi:10.1016/j.jenvman.2012.11.020

Thébaud, O., Doyen, L., Innes, J., Lample, M., Macher, C., Mahévas, S., Mullon, C., Planque, B., Quaas, M., Smith, T., Vermard, Y., 2014. Building ecological-economic models and scenarios of marine resource systems: Workshop report. Mar. Policy 43, 382-386.

doi:10.1016/j.marpol.2013.05.010

Voinov, A., Bousquet, F., 2010. Modelling with stakeholders 败. Environ. Model. Softw. 25, 1268-1281. doi:10.1016/j.envsoft.2010.03.007

Wattage, P., Mardle, S., Pascoe, S., 2005. Evaluation of the importance of fisheries management objectives using choice-experiments. Ecol. Econ. 55, 85-95. doi:10.1016/j.ecolecon.2004.10.016

Wilen, J.E., 1979. Fishernan Behavior and the Design of Efficient Fisheries Regulation Programsl. J. Fish. Res. Board Can. 36, 855 - 858.

Wilen, J.E., 2006. Why Fisheries Management Fails: Treating Symptoms Rather than the Cause. Bull. Mar. Sci. 78, 529-546. 
Wilen, J.E., Smith, M.D., Lockwood, D., Botsford, L.W., 2002. Avoiding Surprises: Incorporating Fishermen Behaviour into Management Models. Bull. Mar. Sci. 70, 553-575.

Yates, K.L., 2014. View from the wheelhouse: Perceptions on marine management from the fishing community and suggestions for improvement. Mar. Policy 48, 39-50.

doi:10.1016/j.marpol.2014.03.002

Zukowski, S., Curtis, A., Watts, R.J., 2011. Using fisher local ecological knowledge to improve management: The Murray crayfish in Australia. Fish. Res. 110, 120-127.

doi:10.1016/j.fishres.2011.03.020 
Appendix 1 - Relationships between vessel size metrics and behavioural parameters.

\begin{tabular}{|c|c|c|c|c|c|c|c|c|}
\hline Variable & 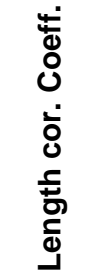 & $\mathbf{n}$ & $\mathbf{p}$ & $\frac{5}{\frac{5}{6}}$ & 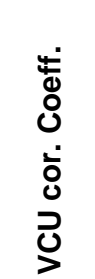 & $\mathbf{n}$ & $p$ & $\frac{5}{5}$ \\
\hline Engine Power & 0.46 & 16 & 0.072 & . & 0.85 & 16 & 0.000 & 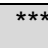 \\
\hline Tonnage & 0.71 & 12 & 0.010 & ** & 0.91 & 12 & 0.000 & *** \\
\hline Average number of crew & 0.84 & 16 & 0.000 & $* * *$ & 0.86 & 16 & 0.000 & $* * \star$ \\
\hline Max number of dredges & 0.7 & 16 & 0.003 & ** & 0.85 & 16 & 0.000 & $* * \star$ \\
\hline Fuel use per towing hour & 0.71 & 13 & 0.007 & ** & 0.86 & 13 & 0.000 & $* \star * \star$ \\
\hline Normal departure distance from port & 0.52 & 16 & 0.039 & * & 0.78 & 16 & 0.000 & *** \\
\hline $\begin{array}{l}\text { Max number of days at sea in relation to king } \\
\text { scallop freshness }\end{array}$ & 0.53 & 16 & 0.034 & * & 0.77 & 16 & 0.001 & $* * *$ \\
\hline Minimum monthly gross required & 0.68 & 5 & 0.204 & & 0.98 & 5 & 0.004 & ** \\
\hline Considered 'good takings' & 0.69 & 16 & 0.003 & ** & 0.66 & 16 & 0.006 & ** \\
\hline Fuel use per steaming hour & 0.7 & 13 & 0.007 & ** & 0.7 & 13 & 0.008 & ** \\
\hline Vessel fuel storage capacity & 0.46 & 15 & 0.087 & & 0.64 & 15 & 0.011 & ** \\
\hline Max number of bags possible to store aboard & 0.68 & 16 & 0.004 & ** & 0.6 & 16 & 0.014 & ** \\
\hline Cost of a days fishing & 0.49 & 14 & 0.078 & . & 0.6 & 14 & 0.023 & * \\
\hline Average steaming speed (knots) & 0.58 & 16 & 0.018 & * & 0.54 & 16 & 0.030 & * \\
\hline Time taken to clear king dredges & 0.45 & 16 & 0.082 & . & 0.52 & 16 & 0.037 & * \\
\hline $\begin{array}{l}\text { Bags per hour (queens) at which would move } \\
\text { location the next day }\end{array}$ & 0.72 & 4 & 0.284 & & 0.95 & 4 & 0.045 & * \\
\hline Minimum viable daily gross & 0.37 & 16 & 0.164 & & 0.49 & 16 & 0.052 & . \\
\hline Minimum daily gross worth fishing for & 0.76 & 9 & 0.017 & * & 0.63 & 9 & 0.067 & . \\
\hline Max steaming speed (knots) & 0.49 & 16 & 0.055 & & 0.41 & 16 & 0.118 & \\
\hline Daily gross at which would consider leaving fishery & 0.68 & 7 & 0.091 & & 0.61 & 7 & 0.145 & \\
\hline Cost of boat upgrades in 5 year period & 0.51 & 11 & 0.113 & & 0.46 & 11 & 0.152 & \\
\hline Number of days a year lost to bad weather & -0.44 & 13 & 0.136 & & -0.39 & 13 & 0.185 & \\
\hline Absolute maximum sea state possible to fish in & 0.34 & 16 & 0.205 & & 0.34 & 16 & 0.194 & \\
\hline Max possible duration of a fishing trip & 0.29 & 16 & 0.270 & & 0.33 & 16 & 0.206 & \\
\hline Cost of boat maintenance per year & 0.69 & 13 & 0.008 & ** & 0.38 & 13 & 0.206 & \\
\hline Percentage of takings as wages & 0.55 & 8 & 0.161 & & 0.48 & 8 & 0.227 & \\
\hline Percentage of catch below MLS & -0.13 & 14 & 0.663 & & -0.34 & 14 & 0.236 & \\
\hline $\begin{array}{l}\text { Max number of days possible at sea in relation to } \\
\text { food supplies }\end{array}$ & -0.14 & 13 & 0.637 & & -0.34 & 13 & 0.249 & \\
\hline $\begin{array}{l}\text { Max sea state would normally prefer not to fish } \\
\text { above }\end{array}$ & 0.28 & 16 & 0.285 & & 0.3 & 16 & 0.255 & \\
\hline Average hours at sea fishing for king scallops & 0.5 & 16 & 0.051 & * & 0.27 & 16 & 0.310 & \\
\hline Maximum distance travelled from port & 0.45 & 14 & 0.103 & & 0.25 & 14 & 0.390 & \\
\hline
\end{tabular}




\begin{tabular}{|c|c|c|c|c|c|c|}
\hline King catch rate at which would move location & 0.15 & 16 & 0.578 & 0.23 & 16 & 0.400 \\
\hline Considered 'too long' to spend at sea & -0.06 & 10 & 0.860 & -0.3 & 10 & 0.407 \\
\hline Maximum gape of trawl net & 0.43 & 15 & 0.108 & 0.23 & 15 & 0.411 \\
\hline $\begin{array}{l}\text { Max number of days at sea in relation to queen } \\
\text { catch freshness }\end{array}$ & 0.18 & 16 & 0.503 & 0.21 & 16 & 0.435 \\
\hline Max wave height possible to fish at & 0.45 & 14 & 0.104 & 0.21 & 14 & 0.466 \\
\hline $\begin{array}{l}\text { Smallest distance willing to fish near another vessel } \\
\text { (miles) }\end{array}$ & 0.31 & 16 & 0.239 & 0.18 & 16 & 0.506 \\
\hline Bag size $(\mathrm{kg})$ & 0.14 & 16 & 0.617 & 0.15 & 16 & 0.597 \\
\hline $\begin{array}{l}\text { How often information from other vessels is taken } \\
\text { into account when deciding fishing location }\end{array}$ & -0.2 & 14 & 0.483 & -0.13 & 14 & 0.667 \\
\hline How much of fishing is in same area as past year & -0.39 & 16 & 0.131 & -0.11 & 16 & 0.697 \\
\hline Time taken to clear queen trawl nets & 0.32 & 13 & 0.288 & -0.11 & 13 & 0.720 \\
\hline King dredge belly ring size & -0.13 & 14 & 0.657 & -0.1 & 14 & 0.721 \\
\hline Number of days a year lost to planned maintenance & 0.09 & 14 & 0.765 & 0.09 & 14 & 0.758 \\
\hline Minimum market price at which would fish (kings) & -0.55 & 8 & 0.160 & -0.03 & 8 & 0.894 \\
\hline $\begin{array}{l}\text { Lowest monthly 'wage' below which would consider } \\
\text { leaving fishery }\end{array}$ & -0.02 & 4 & 0.984 & -0.1 & 4 & 0.904 \\
\hline $\begin{array}{l}\text { Max number of days at sea in relation to fuel } \\
\text { capacity }\end{array}$ & -0.11 & 15 & 0.398 & 0.03 & 15 & 0.904 \\
\hline How many vessels would tolerate within $1 \mathrm{~nm}$ radius & -0.15 & 13 & 0.621 & 0.03 & 13 & 0.920 \\
\hline $\begin{array}{l}\text { Minimum market price at which would fish } \\
\text { (queenies) }\end{array}$ & -0.38 & 10 & 0.278 & -0.02 & 10 & 0.956 \\
\hline $\begin{array}{l}\text { Catch per dredge hour at which would move } \\
\text { location }\end{array}$ & 0 & 16 & 0.990 & 0.01 & 16 & 0.960 \\
\hline Catch per gape length at which would move location & -0.56 & 6 & 0.248 & 0.01 & 6 & 0.984 \\
\hline Number of other vessels information shared with & 0.21 & 16 & 0.442 & -0.01 & 16 & 0.985 \\
\hline $\begin{array}{l}\text { Number of days lost to unplanned mechanical } \\
\text { failure }\end{array}$ & 0.34 & 13 & 0.249 & 0 & 13 & 0.992 \\
\hline
\end{tabular}

